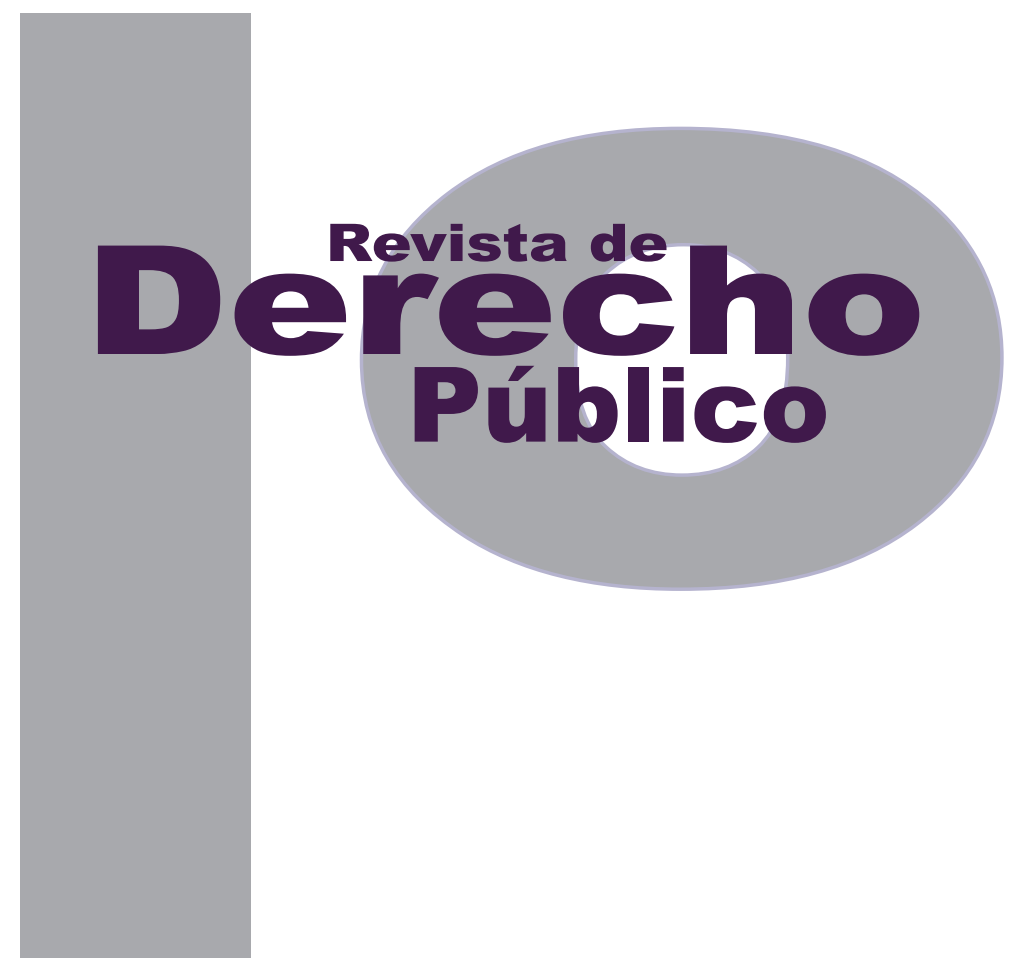

\title{
REPARAR EL SILENCIO: JUSTICIA PARA LOS DAÑOS LINGÜÍSTICOS CAUSADOS POR COLONIZACIÓN Y CONFLICTO
}

\author{
BRETT TODD
}

Universidad de los Andes

Facultad de Derecho

Revista de Derecho Público N. ${ }^{\circ} 31$

Julio - Diciembre de 2013. ISSN 1909-7778 


\title{
Reparar el silencio: justicia para los daños lingüísticos causados por colonización y conflicto*
}

\author{
Brett Todd**
}

RESUMEN

Este artículo propone un concepto de justicia reparativa lingüística para los pueblos indígenas, es decir, medidas de reparación que abordan las consecuencias de la conquista y colonización para las lenguas indígenas. Se presta atención especial a Colombia, donde las culturas de las comunidades indígenas han sido afectadas por el conflicto armado, y se analiza si la reciente Ley de Lenguas Nativas (Ley 1381 de 2010) puede desempeñar una función reparativa en el marco de la justicia transicional.

PALABRAS CLAVE: justicia reparativa, Ley 1381 de 2010, Colombia, restitución, pueblos indígenas, cultura, lenguas.

\section{ABSTRACT}

This article considers a concept of linguistic reparative justice for indigenous peoples, that is, reparative measures addressing the consequences of conquest and colonization on indigenous languages. Particular attention is given to Colombia, where the cultures of indigenous communities have been further afflicted by the armed conflict, in regards to whether the recent native languages law can play a remedial role.

KEY WORDS: Reparative justice, Native Languages Law 1381 of 2010, Colombia, restitution, indigenous peoples, culture, languages.

Citar este artículo como: Todd, B. (Diciembre, 2013). Reparación de los silencios: justicia reparativa para los daños lingüísticos causados por colonización y conflicto. Revista Derecho Público, 31.

\footnotetext{
Abogado graduado de la Universidad de Sydney; maestría en lingüística aplicada de la Universidad de New South Wales, donde actualmente cursa su doctorado en ciencia política y relaciones internacionales. Trabaja en programas de estudios internacionales en la Universidad de Tecnología de Sydney. Correo: Brett.Todd@uts.edu.au

Quiero expresar mi aprecio a Julieta Lemaitre, Libardo Ariza y sus colegas en la Facultad de Derecho de la Universidad de los Andes por invitarme a participar en esta publicación, y por el trato excepcional que me dieron durante mi estadía en 2011 como investigador invitado, en el Centro de Investigaciones Sociojurídicas (CIJUS). Asimismo agradezco las sugerencias, correcciones y otras formas de ayuda que he recibido de varias personas durante los procesos de redacción y edición de este artículo: Stuart Langeveldt, Andrea López, Juan Vicente Herrera, Juliana Vargas, Paulo Bacca, Jan Paul Castellanos Brieva, Fernando Serrano, Irene Baghoomians, Lucas Lixinski, y Brad Condon. También fui afortunado por conocer al abogado Juan David Castillo García, de quien aprendí mucho sobre el pasado y presente de Colombia; dedico este artículo a su memoria.
} 


\section{SUMARIO}

Introducción - I. CAUSAS Y CONSECUENCIAS DE DAÑOS LINGÜÍSTICOS - A. Cómo se produce la pérdida del idioma - B. Importancia de la lengua para la identidad y la cultura - C. Reivindicaciones de los pueblos y organizaciones indígenas respecto a sus lenguas - II. JUSTIFICACIONES PARA LAS REPARACIONES - A. El debate teórico sobre la reparación de los pueblos indígenas - III. NORMAS INTERNACIONALES RELEVANTES CON DERECHOS LINGÜÍSTICOS Y LA PROTECCIÓN DE LENGUAS - A. Obligaciones estatales en la época de derechos humanos - B. Obligaciones en la época de consolidación de los derechos indígenas - C. Orientaciones sobre la aplicación de los instrumentos internacionales - D. Derecho a reparación por violación de normas internacionales - E. Reparación por pérdida de lenguas como consecuencia de etnocidio - F. Jurisprudencia orientada a la protección del idioma - IV. ¿EN QUÉ PUEDE CONSISTIR LA JUSTICIA REPARATIVA LINGÜÍSTICA? - A. Enfoques reparativos aplicables al daño lingüístico - B. Panorama de acciones estatales de posible carácter reparativo - C. Otros elementos aptos para la justicia reparativa de la lengua - V. EL CASO COLOMBIANO: POSIBILIDADES DE JUSTICIA REPARATIVA LINGÜÍSTICA - A. Lo que está en juego: la diversidad lingüística de Colombia - B. Un posible marco para la justicia reparativa lingüística en Colombia - C. Necesidad de implementación y coherencia - VI. CONCLUSIÓN - Bibliografía. 


\section{Introducción}

La expansión europea desde el siglo XV ha ocasionado múltiples destrucciones en las sociedades conquistadas: usurpación de tierras, violencia física, dislocación de estructuras sociales, interrupción de los patrones de subsistencia económica y disrupción profunda de los sistemas culturales. Como parte del impacto cultural, las lenguas autóctonas fueron debilitadas y en muchos casos sustituidas completamente por idiomas europeos. Esto, sin duda alguna, ha significado la pérdida de uno de los principales elementos de identidad cultural y social: la lengua. Tomando nota de los debates recientes relacionados con la intención de resarcir a sujetos colectivos por las injusticias históricas, ${ }^{1}$ este artículo examinará, en términos generales, si debe haber reparación específica por los "daños lingüísticos" experimentados por los pueblos originarios durante diversos procesos de colonización.

De manera puntual, este artículo se concentrará en la viabilidad de una "justicia reparativa lingüística" en Colombia, país caracterizado por un largo conflicto armado, donde se están adelantando medidas legislativas que tienen por objeto establecer formas de reparación a las víctimas. Para facilitar las comparaciones con otros países

1 Por ejemplo, dos noticias de mediados de 2013 dieron cuenta del acuerdo del Reino Unido de ofrecer disculpas y pagar una compensación a las víctimas de los abusos cometidos por sus funcionarios y soldados durante la rebelión Mau-Mau en Kenia en los 1950 (Agencia EFE, 2013), y de la decisión conjunta de los países miembros de la Comunidad del Caribe (CARICOM) de acudir ante la Corte Internacional de Justicia en busca de reparaciones por parte de Francia, Reino Unido y Holanda por la esclavitud y el genocidio contra afrodescendientes y pueblos nativos en el Caribe (Castle, 2013) por parte de los países europeos responsables. colonizados $^{2}$ y las referencias a los instrumentos de derecho internacional, este texto se focalizará en la situación de los pueblos indígenas, pero muchas de las ideas y conclusiones aquí desarrolladas son perfectamente aplicables a la diáspora afrodescendiente en las Américas, que igualmente ha sufrido y sufre injusticias históricas de esclavitud y discriminación.

\section{CAUSAS Y CONSECUENCIAS DE DAÑOS LINGÜÍSTICOS}

\section{A. Cómo se produce la pérdida del idioma}

El abandono por una comunidad del uso de un idioma y la adopción de otro es algo que ha sucedido a lo largo de la historia humana. ${ }^{3} \mathrm{Nu}$ merosas investigaciones han identificado una serie de factores sociales, económicos, culturales, ambientales y psicológicos que explican por qué ocurre este reemplazo. ${ }^{4}$ Este cambio puede ocurrir lentamente a través del contacto a largo plazo con otra comunidad en circunstancias pacíficas, ${ }^{5}$ o por la migración de poblaciones enteras.

2 Entre ellos mi propio país, Australia.

3 Es importante destacar que hoy en día la extinción de los idiomas está ocurriendo a un ritmo alarmante. Según Harrison (2007), cada 14 días desaparece una lengua. Ninguna parte del mundo es inmune a esta tendencia, pero los pueblos indígenas de las Américas y Australia se ven afectados severamente.

4 Véase, entre otros, Crystal (2000, pp. 68-89); Dixon (1997, pp. 7883); Nettle \& Romaine (2000, pp. 90-93); Krauss (1992, p. 6); Fishman (1991).

5 Por ejemplo, a través de los matrimonios, el intercambio o la participación en actividades económicas y religiosas. 
Sin embargo, como fue el caso de los procesos de expansión hacia el "Nuevo Mundo", la pérdida del idioma ha ocurrido con frecuencia después de una conquista violenta por parte de los hablantes de otra lengua. Las violencias ocurridas en la conquista son notorias: trabajos forzados, conversión religiosa obligatoria, secuestro, castigos crueles, masacres, entre otras. Sin embargo, sigue habiendo violencias que causan ruptura cultural, como por ejemplo en las comunidades indígenas brutalizadas por conflictos en Guatemala en los 1980 y en la Colombia actual. Los actos de violencia que desplazan familias indígenas de sus tierras tradicionales, igual en el siglo XXI que en el siglo XVI, impiden prácticas económicas y culturales, alterando la transmisión de la lengua de padres a hijos.

El proceso de abandono del uso de una lengua ha solido continuar durante los siglos de dominación colonial y postcolonial. Baste recordar los intentos oficiales de desincentivar o prohibir el uso de lenguas autóctonas, especialmente en escuelas donde los estudiantes eran castigados por haber pronunciado alguna palabra en su lengua nativa ${ }^{6}$ y cuando se trató de internar niños indígenas lejos de sus familias; en ambos se logró interrumpir la transmisión milenaria de la lengua, creencias religiosas y conocimientos tradicionales. Tales prácticas encajaban perfectamente con políticas de construcción de Estado-Nación que buscaban erradicar las diferencias culturales dentro de las fronteras y asimilar

6 Abusos que también se presentaron en el caso de muchas minorías europeas, por ejemplo, contra el galés y el escocés gaélico en Gran Bretaña y contra el bretón en Francia. Véase, por ejemplo, Edwards (2010) y Nettle \& Romaine (2000). a los pueblos indígenas en las masas trabajadoras de los Estados postcoloniales.

La asimilación forzada ya no es común, pero perduran las presiones que promueven el abandono de las lenguas tradicionales. Por ejemplo, se continúa estigmatizando el uso de las lenguas nativas, hecho que no solo resulta en una disminución de su uso público en ámbitos sociales mixtos, sino que con el tiempo puede tener un impacto negativo aún dentro de contextos puramente indígenas. De otra parte, las lenguas de los grupos sociales dominantes tienden a estar asociadas con un mayor prestigio (Fishman, 1991), por lo cual, incluso si no hubiera discriminación en contra del uso de lenguas minoritarias los hablantes de estas preferirían el idioma del grupo mayoritario por las oportunidades económicas o el estilo de vida mejor que, generalmente, les ofrece. Si padres bilingües deciden criar a sus hijos en la lengua mayoritaria, esta segunda generación tendrá menos conocimiento de la lengua ancestral, y la tercera generación puede ser completamente monolingüe en la lengua dominante. Es esta ruptura en la transmisión intergeneracional la que causa el cambio lingüístico en una comunidad, y si esta tendencia es generalizada en todas las zonas de uso del idioma tradicional puede llegar a su extinción. ${ }^{7}$

Cada comunidad tiene sus propias circunstancias, y en muchos casos la misma resistencia mostrada contra siglos de opresión colonial le

7 Para mayor información al respecto véase, por ejemplo, Unesco (2003), Nettle \& Romaine (2000), Tsunoda (2005). 
ha servido para mantener vivas la fidelidad a la tradición y la continuidad de la práctica lingüística dentro del ámbito familiar. Sin embargo, en el contexto actual, muchas de las fuerzas que llevan a los individuos y a las comunidades a sustituir sus lenguas tradicionales por lenguas mayoritarias no parecen, a primera vista, ser agobiantes en absoluto. Desde el proceso poscolonial, las interacciones cotidianas entre las comunidades indígenas y la sociedad dominante se realizan, en general, a través de las lenguas mayoritarias. A pesar de los esfuerzos actuales para incluir los idiomas ancestrales en las escuelas de las comunidades indígenas, la mayor parte de las clases se dictan en la lengua dominante, y aún más en el nivel postsecundario. A lo anterior se suman los medios de comunicación electrónicos que han hecho incursiones cada vez más profundas en las comunidades indígenas, utilizando casi siempre la lengua dominante.

La cuestión, entonces, es poder evaluar hasta qué punto los individuos son capaces de resistir la presión de tantos factores y conservar su idioma tradicional por lo menos al interior de sus comunidades y familias, o si, definitivamente, se rinden y optan por preferir la lengua dominante. ${ }^{8}$

\section{B. Importancia de la lengua para la identidad y la cultura}

Para cualquier comunidad de seres humanos el idioma que utiliza es una parte fundamental

8 De hecho, Mufenwe (2005) sostiene que el actual escenario de las lenguas en peligro "no fue establecido por opresivas fuerzas históricas, sino por paulatinos procesos de cambio de idioma resultado de una acumulación de decisiones independientes de los individuos". de la cultura propia y, a veces, una marca esencial de su identidad étnica. La lengua ha sido un tema importante en los proyectos nacionalistas o autonomistas, ${ }^{9}$ y su papel en la formación de proyectos etnoculturales ha sido ampliamente reconocido por estudiosos de fenómenos como el nacionalismo, el separatismo, el racismo, el multiculturalismo, los derechos de las minorías y la etnicidad. ${ }^{10}$

La lengua también sirve como vehículo de transmisión cultural intergeneracional. Una comunidad que deja de usar su idioma ancestral no necesariamente pierde su identidad y su carácter distintivo, de hecho, es posible ver un cambio en las prácticas lingüísticas meramente como otra faceta de los procesos dinámicos que ocurren en cualquier cultura, por muy antigua e inmutable que pueda parecer a la mirada occidental. Sin embargo, este cambio lingüístico no puede ocurrir sin que ello suponga cierta disminución en las diversas formas de conocimiento ancestral sobre su relación con otras comunidades, con la naturaleza y con el mundo espiritual.

El conocimiento ambiental tradicional es una parte importante de lo que se puede perder, incluyendo información etnobotánica o etnomedicinal. Varios estudios han demostrado que la pérdida de estos conocimientos podría privar a la humanidad entera de técnicas de gestión ambiental útiles para hacer frente a los contemporáneos cambios del ambiente, de plantas

\footnotetext{
9 Por ejemplo, en Bélgica, Quebec, Cataluña, País Vasco, Bangladesh y zonas de la India.

10 Entre ellos, Herder, Renan, Kedourie, Armstrong, Billig, Hobsbawm, Gellner, Kymlicka y Anthony D. Smith.
} 
cuyo cultivo contribuiría a alimentar la exorbitada población del planeta o de la clave para encontrar la cura de enfermedades. ${ }^{11}$ Como se ve, para justificar acciones dirigidas a la defensa de la diversidad lingüística se suele citar consecuencias que van más allá de los efectos que su pérdida produce en los grupos que hablan las distintas lenguas. ${ }^{12}$

Del mismo modo, existen argumentos que consideran la desaparición de un idioma como una tragedia para la lingüística, ya que representa la pérdida de oportunidades para estudiar otras formas del lenguaje e incluso llegar a conclusiones importantes en estudios de neurociencia, del desarrollo de la humanidad o de las diversas culturas. También hay quienes reconocen la importancia de cada lengua para el patrimonio cultural de una nación o de toda la humanidad, es decir, todos sufrimos su pérdida aunque ni nosotros ni nuestros antepasados la hablaran. Estos argumentos tienen valor y pueden justificar acciones para fortalecer el uso de un idioma - o por lo menos para documentarlo con suficiente detalle para que algunos de sus conocimientos se mantengan-, lo cual es compatible con la posibilidad de ofrecer apoyo a un específico pueblo indígena que corra el riesgo de perder el uso de su lengua ancestral.

11 Harrison (2007), Maffi (2001), Nettle \& Romaine (2000), Edwards \& Heinrich (2006) incluyen ejemplos específicos con respecto a las técnicas de gestión ambiental de los aborígenes australianos, que garantizan la sostenibilidad desde hace milenios y pueden ayudar al país a hacer frente a un aumento previsto de la frecuencia y ferocidad de los incendios forestales.

12 La ONG internacional Terralingua -cuyo índice de diversidad lingüística muestra un declive del $20 \%$ en la diversidad lingüística global entre 1970 y 2005 - se concentra en apoyar la "diversidad biocultural". Harmon y Loh (2010). Preocupaciones similares son estudiadas en los congresos y publicaciones de la Sociedad de Etnobiología.
Sin embargo, los fundamentos de un concepto de justicia reparativa lingüística no se basan en la conveniencia de proteger la diversidad de idiomas por el beneficio que esto representa para el patrimonio de la humanidad, el avance científico o cualquier otro argumento que sea ajeno a las experiencias, realidades o preferencias de las comunidades en las cuales se hablaban o se hablan lenguas tradicionales. Por el contrario, aunque las anteriores razones la fortalecen, la justificación principal de un esfuerzo de justicia reparativa lingüística sería proveer una forma de reparación a un pueblo que, como resultado de las experiencias históricas injustas, ha perdido o corre el riesgo de perder un idioma que desde tiempos remotos le servía o le sirve como medio de comunicación, clave de su autodefinición y vehículo para la transmisión de prácticas culturales y conocimientos tradicionales.

\section{Reivindicaciones de los pueblos y organizaciones indígenas respecto a sus lenguas}

La importancia de las lenguas ancestrales ha sido fuertemente resaltada en las reivindicaciones formuladas por los representantes de las comunidades aborígenes de los diversos países. Los pioneros de movimientos indígenas del siglo XX señalaron que las injusticias a las que fueron sometidos incluyeron la negación de su derecho a tener sus lenguas presentes en los sistemas educativos; ${ }^{13}$ sus quejas y demandas específicas para la restauración de la lengua y la cultura tradicional hicieron parte de las plata-

13 Incluido Manuel Quintín Lame, en Colombia, quien fue elegido defensor de los cabildos indígenas en 1910. Véase Lemaitre Ripoll (2013). 
formas presentadas por las organizaciones que surgieron a lo largo de las Américas, Australia, Nueva Zelanda, Hawái y los territorios de los sami (lapones) en los países escandinavos, en las décadas de los 60 y $70^{14}$ y que en Colombia estuvieron lideradas por el Consejo Regional Indígena del Cauca (CRIC) en 1972 y la Organización Nacional Indígena de Colombia (ONIC) en 1982. Como consecuencia, muchas comunidades comenzaron a establecer, con o sin apoyo oficial, programas de educación bilingüe intercultural $^{15} \mathrm{e}$ iniciaron otras acciones orientadas a fortalecer su idioma propio.

En la mayoría de los lugares mencionados las organizaciones indígenas han tenido que dedicar gran parte de su atención a las cuestiones que giran en torno al control de la tierra y sus recursos, así como a la lucha por una mayor autonomía y por el respeto de los derechos humanos, haciendo frente a una oposición a veces violenta. Por lo tanto, su defensa de los idiomas puede parecer de una prioridad menor, ya que rara vez ha ganado la atención de los medios de comunicación. Sin embargo, no ha desaparecido de los discursos reivindicativos de las organizaciones $^{16} \mathrm{y}$, sobre todo, los miembros de la

$14 \mathrm{Y}$ posteriormente por los movimientos que surgieron entre poblaciones indígenas en regiones como el ártico ruso, Taiwán, Nepal, las Filipinas y Botsuana.

15 En Colombia, por lo general, ha sido denominada etnoeducación. Es importante tener en cuenta que el uso del idioma nativo es solo una parte de ese modelo educativo y de lo que las organizaciones indígenas han buscado. Sus demandas han incluido un mayor control sobre la educación en sus comunidades, el aumento de las perspectivas no occidentales con los enfoques indígenas al conocimiento y el aprendizaje, y el desarrollo endógeno de los procesos educativos.

16 Véase, por ejemplo, el mandato general emitido por el VII Congreso de los Pueblos Indígenas de la Organización Nacional Indígena de Colombia, en 2007. comunidad con fuertes intereses en la cultura, la educación y el patrimonio lingüístico no se han cansado de trabajar en este campo, incluso cuando han carecido de financiación y apoyo institucional.

Los movimientos indígenas que han conformado redes internacionales no solo han reiterado sus demandas acerca de los derechos lingüísticos y el reconocimiento y la revitalización de sus idiomas, sino que han llegado a tener incidencia y formas de participación directa en los foros internacionales -entre ellos, las Naciones Unidas $^{17}$ y las entidades asociadas-, lo que les ha permitido incidir en la elaboración de normas de derecho internacional que responden a algunas de estas demandas. ${ }^{18}$ Más recientemente se ha hecho hincapié en los documentos del Foro Permanente para las Cuestiones Indígenas ${ }^{19}$ y del Mecanismo de Expertos sobre los Derechos de los Pueblos Indígenas. ${ }^{20}$ En Colombia, los pue-

17 Los informes elaborados por José Martínez Cobo para la onU sobre la situación de los pueblos indígenas del mundo entre 1981-83 incluyeron un capítulo sobre la protección de las lenguas y la aplicación de los derechos conexos, otro centrado en el tema de la educación y concluyó con varias recomendaciones sobre el tipo de medidas que deben adoptar los Estados miembros con respecto a estos temas.

18 Se destacan el Convenio 169 sobre pueblos indigenas y tribales de la OIT (Convenio 169 оाт) y la Declaración de las Naciones Unidas sobre los derechos de los pueblos indígenas (DDPI), considerados más adelante.

19 La cuestión de las lenguas indígenas amenazadas fue objeto de un informe en el 2008, y esta preocupación fue reiterada en la publicación del Foro sobre la situación de los pueblos indígenas del mundo (UNPFII, 2010).

20 Este órgano subsidiario del Consejo de Derechos Humanos de las Naciones Unidas está llevando a cabo una consulta con el objetivo de realizar un estudio "sobre el papel de las lenguas y la cultura en la promoción y protección de los derechos indígenas y la identidad" (http://www.ohchr.org/Documents/Issues/IPeoples/EMRIP/NVConsultationLanguagesCulture_sp.pdf) y continúa el estudio de 2009 sobre los obstáculos a la aplicación de derechos indígenas a la educación (http://www.ohchr.org/Documents/Issues/IPeoples/EMRIP/A_HRC_ EMRIP_2009_2_sp.pdf). 
blos indígenas llevan cuatro décadas alertando al Estado sobre la importancia de sus lenguas y el riesgo de extinción en que se encuentran, mensaje que ahora mismo es reforzado en el plano internacional.

\section{JUSTIFICACIONES PARA LAS REPARACIONES}

\section{A. El debate teórico sobre la reparación a los pueblos indígenas}

El peso de las razones mencionadas -tanto por los mismos miembros de los pueblos como por los observadores externos-sería suficiente para sostener la opinión de que cualquier pérdida o debilitamiento de los idiomas ancestrales equivale a un perjuicio en términos de cultura e identidad; en otras palabras, es posible afirmar que se ha producido el "daño lingüístico". Esta afirmación lleva al interrogante primordial de este artículo: ¿pueden los pueblos que han sufrido daño lingüístico ser titulares de algún tipo de reparación? Como se verá, existe justificación suficiente para contestar positivamente si se habla en términos morales, pero no es menos cierto si se responde desde la perspectiva jurídica.

En el derecho internacional el término "reparaciones" se refiere a los remedios disponibles para subsanar ciertos daños ocasionados como resultado de la violación de las normas internacionales. ${ }^{21}$ Las reparaciones efectuadas durante el último siglo se caracterizaron por ser indemni-

21 Ver, por ejemplo, Grieff (2006) y Shelton (2005). zaciones económicas pagadas a determinados grupos de personas, como los civiles estadounidenses de origen japonés internados en el "centro de reubicación" en 1942 por el gobierno norteamericano o las víctimas del gobierno militar argentino de 1976-1983. ${ }^{22}$ A nivel conceptual estos casos presentan características que facilitan la justificación de la compensación a título de reparación: la posibilidad de identificar el daño sufrido por un grupo de personas, también identificables, como resultado de actos ilícitos cometidos por, o atribuibles a, un Estado soberano, y el haberse presentado en un lapso relativamente corto entre la comisión del acto nocivo y la realización de las reparaciones.

Juristas como Lenzerini (2008), Francioni (2008), Charters (2008), Shelton (2005), Tsosie (2007) y Thompson (2002) han examinado la situación de los pueblos indígenas en cuanto a su derecho a la justicia reparativa e identificado los enfoques restaurativos como idóneos para poder establecer relaciones armónicas en sociedades forjadas en medio de los traumas de la colonización. Estas posiciones han sido controvertidas por argumentos ${ }^{23}$ que señalan que existe una diferencia trascendental entre

22 El pago de reparaciones por un Estado vencido en guerra al Estado vencedor, como la indemnización pagada por Paraguay después de la Guerra de la Triple Alianza o por Alemania después de la Primera Guerra Mundial, parece estirar el concepto al dirigir la reparación a un Estado en vez de a un grupo de personas; sin embargo, encaja con la perspectiva de Lenzerini (2008) de que las normas sobre reparaciones entre Estados soberanos pueden servir de modelo para reparar a colectividades indígenas, ya que estas mantienen su soberanía a pesar de las pretensiones de los Estados postcoloniales de darla por terminada.

23 Véase, por ejemplo, Waldron (1992) y Posner y Vermeule (2003). Cabe mencionar la gran polémica sobre el tema de reparación histórica en las negociaciones del texto de la Declaración y el Programa de Acción de Durban, en 2001. 
las reparaciones realizadas por ciertas injusticias históricas del siglo XX y la posición de los pueblos indígenas al respecto. En efecto, mientras que en las primeras por lo general ha sido posible identificar a las víctimas de los daños en cuestión y a las personas o entidades directamente responsables, en el caso de los pueblos indígenas la situación es precisamente la opuesta, pues muchos daños se cometieron en el pasado lejano, de modo que ni las víctimas (ni sus herederos inmediatos) ni los victimarios son identificables. El mismo razonamiento se utiliza contra las reclamaciones de reparación por la esclavitud interpuestas por parte de algunos afrodescendientes. ${ }^{24}$

No obstante, los autores en favor de los procesos de reparación demuestran que las injusticias relevantes no fueron cometidas solamente en los primeros momentos de la conquista, hace siglos, sino que ha habido una continuación de abusos, como usurpación y desposesión sostenida de tierras y recursos, discriminación, marginalización y negación de derechos de toda índole. Los perjudicados siguen estando vivos, o sus hijos y nietos lo están, de manera que no es difícil identificar los grupos que merecen recibir reparación ni las personas o instituciones responsables. ${ }^{25}$

24 Véase, por ejemplo, Posner y Vermeule (2003). Como destacó Valls (2007), el concepto de reparación para los afrodescendientes se puede caracterizar como referible a la "historia entera de la injusticia racial" y, por lo tanto, se extiende más allá de la esclavitud, como lo demuestran las políticas discriminatorias de décadas después de la abolición.

25 Un argumento clave para Waldron (1992) es que la corrección de una injusticia histórica puede resultar en una nueva injusticia. Por ejemplo, si una propiedad adquirida por conquista hace siglos es restituida a los descendientes del ocupante originario, el tercero que la había comprado en buena fe sufre una injusticia. Sin embargo, esta perspectiva
Aunque gran parte de la literatura en consideración se centra en reparaciones sobre tierras, hay amplia aceptación de la conveniencia de reparar por daños económicos, psicosociales y culturales, y a veces se cita lo lingüístico en la categoría de perjuicios culturales. ${ }^{26}$ Hasta el momento, rara vez se ha analizado la idea de reparaciones dirigidas específicamente a resarcir perjuicios a las prácticas lingüísticas de los pueblos indígenas. Dussias (2008) considera que algunos planteamientos recientes en el debate sobre las reparaciones son útiles para pensar en las responsabilidades de los Estados Unidos hacia las lenguas indígenas. Para este autor, el enfoque de las "cuatro Rs" de justicia reparati$v^{27}$ presentado por Yamamoto et al. (2007) es especialmente apto para evaluar si se han realizado esfuerzos suficientes para proveer la justicia y promover la reparación cuando se trata de lenguas indígenas.

Es importante señalar que el concepto de justicia reparativa orientada a las lenguas indí-

es de dudosa relevancia cuando se trata de algo inmaterial, como una lengua o práctica lingüística.

26 En opinión de Lenzerini (2008, pp. 15-16), el contenido de términos como 'agravio', 'perjuicio', 'pérdida' y 'daño' debe ser evaluado principalmente a través de la percepción de las personas o grupos interesados, lo que es aplicable a una amplia gama de modificaciones a las condiciones que afectan la vida de los pueblos indígenas.

27 Las cuatro Rs son: (1) el RECONOCIMIENTO de los daños infligidos al grupo y las raíces históricas de sus reclamos, (2) la aceptación de la RESPONSABILIDAD por la recuperación de los daños, ya sea basado en la culpabilidad o en la recepción de privilegios y beneficios, (3) los actos de RECONSTRUCCIÓN para construir una nueva relación, incluyendo disculpas, otros actos de expiación y los esfuerzos para reestructurar las instituciones, y (4) las REPARACIONES, como la educación, los gestos simbólicos y el apoyo financiero. Dussias (2008, p. 66) concluye que en los Estados Unidos ha habido progreso, pero hay necesidad de seguir avanzando en acciones de reconstrucción que deberán incluir los cambios en las instituciones educativas para acomodar el aprendizaje de idiomas, y los actos de reparación deben considerar un compromiso financiero más generoso y sostenido para la restauración idioma. 
genas, dada la importancia del idioma para la identidad cultural y la cohesión social, cabe bien en el enfoque de reparación transformadora avanzado en Colombia en los últimos años ${ }^{28}$ y es altamente compatible con el de justicia étnica colectiva planteada por Rodríguez-Garavito y Lam (2011). El carácter netamente colectivo de una justicia reparativa lingüística -en términos tanto de los perjuicios históricos como de las medidas remediales- la hace también muy acorde con la comprensión contemporánea de los derechos indígenas. ${ }^{29}$

Aun si el debate teórico sigue irresuelto es posible señalar dos campos que son prometedores para brindar formas de apoyo a las propuestas de reparación para los pueblos indígenas, incluidas aquellas centradas en la reparación de los daños lingüísticos. En el campo del derecho internacional, las normas desarrolladas en la época moderna de los tratados de derechos humanos podrían justificar algunas medidas reparativas por lo menos para los daños infligidos durante el período en que estas han estado en vigor. La siguiente sección considerará dichas normas y lo que pueden implicar para la justicia reparativa lingüística.

28 Concepto explorado por Uprimny y Guzmán (2010) y citado en la Ley 1448 de 2011

Bacca (2009) anota las dificultades para establecer límites precisos entre las reparaciones masivas y las políticas de aplicación de los derechos económicos, sociales y culturales. Las reparaciones colectivas no pueden reducirse a las políticas sociales que le competen al Estado, de acuerdo con el principio constitucional sobre diversidad étnica y cultural: "Las reparaciones colectivas dependen de los efectos de la violencia que las comunidades indígenas sufren en la coyuntura del conflicto armado interno; la diversidad étnica y cultural es una cuestión de protección especial de DESC derivada del texto constitucional".
El otro campo consiste en la adopción por los Estados colonizadores o postcoloniales de medidas que, aunque no específicamente identificadas como acciones de justicia reparativa, coinciden con un reconocimiento oficial de la comisión de injusticias en el pasado contra los pueblos indígenas o de otras minorías, y que tienen un contenido orientado a afrontar al menos algunos de los efectos negativos de esas injusticias, incluyendo el daño lingüístico. Más adelante serán desarrollados algunos de estos casos, ya que el contenido de esas medidas es útil como modelo parcial para la construcción de posibles medidas de justicia reparativa lingüística.

\section{NORMAS INTERNACIONALES RELEVANTES PARA LOS DERECHOS LINGÜÍSTICOS Y LA PROTECCIÓN DE LENGUAS}

\section{A. Obligaciones estatales en la época de derechos humanos}

Un análisis de las disposiciones de los instrumentos vinculantes para Colombia, más la Declaración Universal de los Derechos Humanos (DUDH) y la Declaración Americana de los Derechos y Deberes del Hombre (DADDH)-ampliamente considerados por tener naturaleza de derecho internacional consuetudinario además de caber dentro del bloque de constitucionalidad-, muestran que como Estado debe garantizar los siguientes derechos y obligaciones a partir de los respectivos años indicados: ${ }^{30}$

\footnotetext{
30 Véase Gafner-Rojas (2008) por un análisis detallado de las normas del derecho internacional aplicables al ordenamiento jurídico colombiano con relevancia para la protección de lenguas indigenas.
} 
Desde 194831:

- Libertad de expresión ${ }^{32}$

- Derecho a participación en la vida cultural ${ }^{33}$

- Derecho a la educación ${ }^{34}$

- Obligación de garantizar a todas las personas, los derechos que se especifican en el instrumento correspondiente, sin discriminación por razón de (entre otras) la raza y la lengua. ${ }^{35}$

\section{Desde 196936:}

- Obligación de enseñar la lectoescritura a los niños indígenas en lengua indígena cuando sea viable ${ }^{37}$

31 Año de la Declaración Americana de los Derechos y Deberes del Hombre y la Declaración Universal de los Derechos Humanos.

$32 \mathrm{DADDH}$, art. 4; DUDH, art. 19. Posteriormente, en el Pacto Internacional de Derechos Civiles y Políticos (PIDCP), art. 19 y la Convención Americana sobre Derechos Humanos (CADH), art. 13

33 DADDH, art. 13; DUDH, art. 27. Posteriormente, en el PIDESC, art. $15 \mathrm{y} \mathrm{el}$ Protocolo de San Salvador (PSS), art. 14.

34 DADDH, art. 12; DUDH, art. 26. Posteriormente, en el Convenio 107 sobre poblaciones indígenas y tribales de la Organización Internacional del Trabajo (Convenio 107 OIT), art. 21; PIDESC C, art. 13; Convención sobre los Derechos del Niño (CDN), art. 28; PSs, arts. 13 y 16; Convenio 169 OIT, art. 26.

35 DADDH, art.2; DUDH, art. 2. Posteriormente, en PIDCP, arts. 2 y 26; PIDESC, art.2; CADH, art.1; PSS, art.3; CDN, art.2; Convenio 169 OIT, art. 3. La Convención Internacional sobre la Eliminación de todas las Formas de Discriminación Racial (CIDR), ratificada por Colombia en 1981, consolida las obligaciones en relación con la no discriminación (véanse arts. 2,5 y 7 ).

36 Año de ratificación por Colombia del Convenio 107 OIT.

37 Convenio 107 оाт, art. 23, reiterado en el Convenio 169 oIT, art. 28; en ambos textos se dispone "o en la lengua que más comúnmente se hable en el grupo", lo cual significa que la utilización del idioma ancestral no es necesaria cuando ya no es lengua materna de los niños en cuestión. Un informe de la Unesco, de 1953, estableció la importancia de usar la lengua materna en los primeros años de educación. (Citado en Skutnabb-Kangas, 2000)
- Obligación de adoptar disposiciones para preservar las lenguas indígenas ${ }^{38}$

- Obligación de difundir a las poblaciones indígenas, a través de sus lenguas si fuere necesario, información sobre sus derechos y deberes. ${ }^{39}$

\section{Desde 1976"4:}

- Derecho del acusado a un intérprete ${ }^{41}$

- Derecho de miembros de un grupo indígena o de una minoría a disfrutar la cultura del grupo y utilizar su idioma ${ }^{42}$

-Obligación de conservar, desarrollar y difundir la cultura. ${ }^{43}$

38 Convenio 107 OIT, art. 23; Convenio 169 oIT, art. 28 agrega el deber de promover el desarrollo y práctica de las lenguas indígenas. Posteriormente, la Convención para la Salvaguardia del Patrimonio Cultural Inmaterial, ratificada por Colombia en 2008, confirmó la obligación de proteger las lenguas (que están específicamente incluidas en la definición de dicho patrimonio).

Convenio 107 оाт, art. 26, reiterado posteriormente en el Convenio 169 OIT, art. 30.

40 Año de entrada en vigor del PIDCP y el PIDESC. Cabe mencionar que Colombia se comprometió a cumplir estas obligaciones en 1969, cuando ratificó ambos pactos.

41

PIDCP, art. 14. También en CADH, art. 8 (ratificada por Colombia en 1973, en vigor desde 1978) y CDN, art. 40. Nota: este se entiende como un derecho procesal, esencial para la justicia de los acusados, por lo que el Comité de Derechos Humanos ha podido señalar que los miembros de un grupo minoritario que dominan la lengua empleada por un tribunal no tienen derecho a un intérprete en el idioma minoritario (Higgins, 2003).

PIDCP, art. 27; posteriormente, CDN, art. 30. EI PIDCP se refiere únicamente a miembros de "minorías étnicas, religiosas o lingüísticas", pero el Comité de Derechos Humanos de la onu incluye explícitamente a los pueblos indígenas en su Observación General $N^{\circ} 23$ sobre el art. 27. (La CDN se refiere tanto a niños indígenas como a niños que pertenecen a minorías).

43 PIDESC, art. 15 
Desde 19914:

- Obligación de orientar la educación para inculcar a los niños el respeto para su identidad e idioma ${ }^{45}$

- Obligación de alentar a los medios para que tengan en cuenta las necesidades lingüísticas de los niños indígenas o minoritarios ${ }^{46}$

- Obligación de adoptar medidas para salvaguardar las culturas de los pueblos indígenas y para promover la plena efectividad de sus derechos culturales, respetando su identidad cultural y tradiciones. ${ }^{47}$

En las últimas décadas, Estados como Australia y Colombia no han incluido prohibiciones explícitas sobre los derechos relacionados con el idioma, ${ }^{48}$ y muchos han adoptado legislaciones o enmiendas constitucionales que reconocen el derecho de los pueblos indígenas a sus lenguas. En este sentido Colombia fue un país pionero con su Constitución de 1991, y la sentencia del Tribunal Constitucional T-384/94 en $1994^{49}$ puso en evidencia que los hablantes de lenguas indígenas tienen el derecho de utilizar su idio-

44 Año de ratificación por Colombia del Convenio 169 oIt y la CDN.

45 CDN, art. 29.

46 CDN, art. 17.

47 Convenio 169 oIt, arts. 4 y 2. Cabe mencionar que el art. 28 contiene la obligación de dar un papel importante a los pueblos respecto a la educación en sus comunidades y art. 27 la de incorporar sus conocimientos y aspiraciones culturales en los programas educativos.

Mientras que otros sí, por ejemplo, a comienzos del siglo XXI comenzaron a levantar las restricciones en el uso del kurdo en Turquía.

49 La sentencia se basó en la CIDR, art. 2 y la cooficialidad acordada por la Constitución. ma en la radio y otros medios de comunicación. Esta protección del derecho constitucional apoya la conclusión de que Colombia no está violando la obligación negativa de no interferir con el derecho de libertad de expresión que implica el libre uso de las lenguas. Sin embargo, un vistazo al anterior listado de obligaciones sugiere que los Estados parte de esos instrumentos deben procurar hacer algo más que simplemente abstenerse de interferir con la libertad de utilizar las lenguas, en otras palabras, se enfrentan a la obligación de adoptar algunas medidas positivas. Cuando se repara en los comentarios hechos por tribunales y organismos internacionales acerca de la aplicación de tales mandatos este aspecto se nota de forma más clara, como se verá más adelante. ${ }^{50}$

\section{B. Obligaciones en la época de consoli- dación de los derechos indígenas}

Más recientemente, la aprobación de la Declaración de las Naciones Unidas sobre los derechos de los pueblos indígenas (DDPI) en 2007 abrió una nueva era de fortalecimiento de los derechos indígenas (tanto individuales como colectivos) y de los deberes de los Estados. De relevancia aquí, el hecho de que la DDPI urge a Ios Estados a “adoptar medidas eficaces" para proteger un amplio derecho respecto de las len-

50 Cabe mencionar la influencia que tienen diversos documentos no vinculantes, como la Declaración sobre los derechos de las personas pertenecientes a minorías nacionales o étnicas, religiosas y lingüísticas de 1992, la Declaración universal de la Unesco sobre la diversidad cultural de 2001, la Resolución de la Asamblea General de la onu 56/262 de 2002, y el Informe del Secretario General de las Naciones Unidas sobre el $58^{\circ}$ período de sesiones (2003). 
guas indígenas ${ }^{51}$ y "asegurar que los pueblos indígenas puedan entender y hacerse entender en las actuaciones políticas, jurídicas y administrativas, proporcionando para ello, cuando sea necesario, servicios de interpretación u otros medios apropiados"; y también "para que las personas indígenas, en particular los niños, incluidos los que viven fuera de sus comunidades, tengan acceso, cuando sea posible, a la educación en su propia cultura y en su propio idioma". 52 Más adelante se volverá sobre cómo contribuye la DDPI al tratamiento de los temas de etnocidio y reparación. ${ }^{53}$

El impacto futuro de la DDPI será mayor si se considera que tiene carácter vinculante y, por lo tanto, de fuerza obligatoria, al igual que las convenciones y tratados, tal como lo sostiene el Foro Permanente para las Cuestiones Indígenas de la onu; en cualquier caso, por lo menos se acelerará la consolidación del derecho internacional consuetudinario relativo a los derechos

51 DDPI, art. 13(1): "Los pueblos indígenas tienen derecho a revitalizar, utilizar, fomentar y transmitir a las generaciones futuras sus historias, idiomas, tradiciones orales, filosofías, sistemas de escritura y literaturas, y a atribuir nombres a sus comunidades, lugares y personas, así como a mantenerlos."

52 DDPI, art. 14(2). El inciso (1) confirma el derecho "a establecer y controlar sus sistemas e instituciones docentes que impartan educación en sus propios idiomas, en consonancia con sus métodos culturales de enseñanza y aprendizaje".

53 La DDPI también exige la adopción de medidas eficaces para asegurar que los medios públicos "reflejen debidamente la diversidad cultural indígena" y para alentar a los medios privados de manera semejante (art. 16). Del mismo modo, otros derechos reconocidos son: la libre determinación del desarrollo cultural (art. 3); "a mantener, controlar, proteger y desarrollar el patrimonio cultural, sus conocimientos tradicionales y las expresiones culturales" (art. 31); "a practicar y revitalizar las tradiciones y costumbres culturales" (art. 11); "a que la dignidad y diversidad de sus culturas, tradiciones, historias y aspiraciones queden debidamente reflejadas en la educación y la información pública" (art. 15). de los indígenas ${ }^{54}$ para, de este modo, aumentar el umbral de responsabilidad estatal con respecto a las obligaciones y su violación. Entonces, si resulta difícil establecer la comisión de una violación por un determinado Estado en el período entre 1948 y 2007, puede ser más fácil identificar la obligación de reparar por acciones u omisiones posteriores a $2007 .{ }^{55}$ Ello, teniendo en cuenta que la falta de respuesta a un "daño lingüístico" (por ejemplo, un descenso continuo en el número de hablantes después de un desplazamiento) resultante de una violación anterior podría considerarse una nueva violación.

\section{Orientaciones sobre la aplicación de los instrumentos internacionales}

Algunos órganos de las Naciones Unidas encargados de velar por el cumplimiento de los instrumentos específicos, o con funciones de supervisión para temas particulares, han emitido observaciones o comentarios que ilustran la aplicación de las disposiciones de mayor relevancia para los derechos lingüísticos y las lenguas. En cada caso el alcance de la disposición en cuestión se revela bastante amplio en cuan-

54 Véase, por ejemplo, Anaya (2004). Ya se cita la DDPI en las interpretaciones de los órganos de la ONU, por ejemplo, en CDESC (2009b). Si se logra establecer un órgano de seguimiento, como el comité dedicado a la DDPI sugerido por Clavero en PFII/2009/EGM1/4, habrá aún más impacto a nivel internacional, posiblemente llegando a los tribunales nacionales.

55 Situación que se fortalecería si se aprueba el Proyecto de Declaración Americana sobre los Derechos de los Pueblos Indígenas, consolidando así la tendencia normativa en América Latina sobre la responsabilidad estatal respecto a la cultura indígena y los derechos conexos (Véase Rodríguez-Piñero (2011) sobre el reforzamiento mutuo entre la jurisprudencia interamericana y los estándares de la DDPI y el Proyecto). Además, la Asamblea General de la Unesco está considerando un nuevo instrumento sobre lenguas amenazadas, por lo que dentro de unos años puede que haya otra declaración, o incluso un convenio, que fortalezca las responsabilidades de los Estados en esta materia. 
to al contenido de los derechos y, por lo tanto, de las "obligaciones negativas" que los Estados enfrentan para no impedir el ejercicio de esos derechos. Sin embargo, esos comentarios hacen énfasis en las acciones positivas que los Estados deben emprender para cumplir con sus obligaciones de cara al tratado.

Por ejemplo, en su Observación General de 2009 sobre la no discriminación ${ }^{56}$, el Comité de Derechos Económicos, Sociales y Culturales (CDESC) señaló que, en la medida de lo posible, la información sobre los servicios públicos debe estar disponible en los idiomas minoritarios en aras de superar las barreras lingüísticas que pueden impedir el ejercicio de los derechos enlistados en el Pacto Internacional de Derechos Económicos, sociales y Culturales (PIDESC). Se refirió a la necesidad de superar los perjuicios históricos sufridos por ciertos grupos y de configurar medidas positivas de forma permanente en casos excepcionales, como los servicios de interpretación para las minorías lingüísticas. ${ }^{57}$

56 CDESC. (2009a). Anteriormente el Comité para la Eliminación de la Discriminación Racial (CERD) de la ONU, que hace declaraciones sobre la CIDR, hizo un llamamiento a los Estados a reconocer y respetar las lenguas indígenas y a promover su conservación (CERD, 1997).

57

Anteriormente el CDESC, en cooperación con la Unesco, había aclarado que el derecho a la educación en el art. 13 del PIDESc incluye dimensiones de no discriminación, pertinencia cultural y capacidad de respuesta a las necesidades de los alumnos en sus contextos culturales y sociales; dijo hacer su interpretación a la luz de la CIDR, la CDN, el Convenio 169 oIт y la Convención de la Unesco relativa a la lucha contra las discriminaciones en la esfera de la enseñanza. La última convención mencionada data de 1960 y reconoce, inter alia, el derecho de los miembros de las minorías de "llevar a cabo sus propias actividades educativas, incluyendo el mantenimiento de las escuelas y, en función de la educación política de cada Estado, el uso o la enseñanza de su propia lengua". Ha sido utilizado como orientación por la Unesco y aceptado por casi cien países, incluyendo Australia y la mayoría de América Latina, pero no por Colombia.
Luego, en el mismo año, el $\operatorname{CDESC}^{58}$ aclaró las obligaciones que incumben a los Estados parte en relación con el derecho a participar en la vida cultural: por ejemplo, para lograr la promoción de la diversidad y el acceso a las expresiones culturales, deben establecer "programas de apoyo a las minorías... en sus esfuerzos por preservar su cultura", y dar apoyo a instituciones públicas, la infraestructura cultural y la radiodifusión pública en las lenguas minoritarias. ${ }^{59}$

El análisis anterior, de tan solo un artículo del mencionado instrumento de derechos humanos, proporciona abundante apoyo al argumento que sostiene que el derecho internacional, en la forma de tratados inequívocamente vinculantes, ha encargado a Estados como Colombia y Australia de responsabilidades importantes en relación con el mantenimiento de su gran diversidad lingüística y el respeto por los derechos lingüísticos de sus ciudadanos indígenas. Obligaciones que, de hecho, han tenido durante décadas.

58 CDESc. (2009b). Nótese que el análisis del Comité sobre el derecho a participar en la vida cultural (PIDESC, art. 15) incorpora referencias al Convenio 169 OIT, DDPI, y las convenciones y la declaración de la Unesco mencionadas anteriormente.

59 Otras obligaciones incluyen las de: asegurar que los programas de educación de los grupos indígenas "se llevan a cabo sobre su propio idioma o en él"; proteger las culturas minoritarias "como un componente esencial de la identidad del estado"; impedir que terceros interfieran en el ejercicio de estos derechos; adoptar políticas para proteger y promover la diversidad cultural y facilitar el acceso a las expresiones culturales; "proporcionar todo lo necesario para el cumplimiento del derecho a participar en la vida cultural cuando los individuos o las comunidades no están en condiciones, por razones ajenas a su voluntad, de ejercer por sí mismos ese derecho con los medios a su disposición”, que incluye los programas "con el objetivo de preservar y restaurar el patrimonio cultural"; adoptar "medidas proactivas que también promueven el acceso efectivo de todos a los bienes culturales intangibles (tales como el lenguaje...)"; y garantizar que se tenga en cuenta el carácter colectivo de este derecho para los pueblos indígenas. 
De otro lado, la jurisprudencia de tribunales nacionales y supranacionales ha arrojado claridad acerca del significado de los instrumentos de derechos humanos en cuestiones de preservación del idioma y derechos lingüísticos. Estos últimos han tenido más éxito en Europa, donde se ha desarrollado una serie de tratados y recomendaciones que especifican las acciones positivas de los Estados en cuanto a apoyar los derechos lingüísticos de las minorías. ${ }^{60}$

Para el caso colombiano resulta relevante que la Corte Interamericana de Derechos Humanos (Corte IDH) haya interpretado la Convención Americana sobre derechos Humanos (CADH) de manera más amplia de lo que una simple lectura podría sugerir. ${ }^{61}$ Por ejemplo, la sentencia relativa a la Comunidad Indígena Xákmok Kásek vs. Paraguay (2010) interpretó varios derechos en la CADH a la luz del Convenio 169 de la Organización Internacional del Trabajo (Convenio 169 оІт), lo que confirma la obligación del Estado de adoptar medidas especiales para proteger los derechos humanos de los niños indígenas, incluida la provisión de educación culturalmente apropiada. En López Álvarez vs. Honduras (2006), el mismo tribunal interpretó la libertad

60 Por ejemplo, la Carta Europea de Lenguas Regionales o Minoritarias de 1992. Véase, Gorter y Cenoz (2012), Varennes (2007) y Higgins (2003). Aunque tales documentos no pueden ser vinculantes fuera de las jurisdicciones adscritas, no se puede excluir que un tribunal latinoamericano considere su contenido en la interpretación de un instrumento internacional o del hemisferio occidental.

61 Por ejemplo, en Pueblo Saramaka People vs. Suriname (2007) se refirió al PIDESC y al PIDCP en su interpretación de la CADH, ya que el art. 29(b) de la CADH no permite dar a sus derechos una construcción más estrecha que lo encontrado en cualquier otro tratado en que el Estado es Estado parte. Como lo ha notado Pasqualacci (2006, p. 284), la Corte IDH se convirtió en el primer organismo judicial internacional en dar su imprimatur a una interpretación progresiva de una amplia gama de derechos indígenas y de los principios relacionados. de expresión consagrada en el artículo 13 de la CADH para que incluyera el derecho a hablar en su lengua materna.

Los órganos de la onu también evalúan las denuncias individuales sobre violaciones de los derechos reconocidos en los tratados respectivos. Mientras que el Comité de Derechos Humanos $(\mathrm{CDH})$ se ha mostrado reticente a encontrar violaciones del artículo 27 del Pacto Internacional de Derechos Civiles y Políticos (PIDCP) que reconoce el derecho de miembros de minorías a disfrutar de su cultura, por lo general señalando que las acciones estatales en cuestión fueran razonables y el daño a la comunidad insuficiente para constituir una violación de los derechos culturales garantizados por el artículo 27 (Shelton, 2005), sí ha avanzado en sus conclusiones sobre el artículo 26 (la discriminación), por ejemplo, al considerar que una política estatal que requiere el uso exclusivo de una sola lengua para efectos administrativos debe ser razonable. ${ }^{62}$ En suma, estos comités de la onu aplican las normas internacionales vigentes, por lo que es probable que la evolución de las concepciones de los derechos indígenas vaya a provocar un cambio correspondiente en futuras determinaciones. ${ }^{63}$

62 En este caso, el Comité de Derechos Humanos decidió que el requisito de que las comunicaciones escritas y orales entre los funcionarios públicos y el público sea en inglés, incluso cuando ambas partes fueran capaces de comunicarse en otro idioma, constituía una discriminación inaceptable contra las personas con una lengua materna distinta: Diergaardt vs. Namibia (2000), considerado en Higgins (2003).

63 Sin embargo, no será necesariamente inmediato. El Comité de Derechos Humanos se mostró inconsecuente con los estándares evolutivos en su sentencia de 2009 en Ángela Poma Poma vs. Perú, que reconoce el principio de consentimiento previo libre e informado, pero todavía no acepta la inclusión de pueblos indígenas en la definición de "pueblos" en el PIDCP, Art. 1. Véase Göcke (2010). 


\section{Derecho a reparación por violación de normas internacionales}

Los diversos derechos y obligaciones suelen reforzarse con instrumentos que imponen la adopción de medidas necesarias para hacer efectivos los derechos. ${ }^{64}$ Sin embargo, ¿qué pasa si un Estado directa o indirectamente no cumple con sus obligaciones?

La mayoría de las disposiciones consideradas contienen artículos que autorizan la reparación por parte de los Estados que no hayan cumplido con sus obligaciones. ${ }^{65}$ La falta de tal cláusula, entre otros, en la Convención sobre los Derechos del Niño (CDN) y el PIDESc, no impide resarcir un daño: es un principio bien establecido por el derecho internacional -subrayado en repetidas ocasiones por la Corte $\mathrm{IDH}^{66}$ - que un Estado está obligado a reparar cuando, por un acto $u$ omisión atribuible a él mismo, no haya cumplido con una obligación en virtud del derecho internacional. ${ }^{67}$ Por ello, si los tribunales nacionales no están dispuestos o no están en capacidad de hacer frente a una demanda de forma adecuada, una instancia supranacional

64 Por ejemplo, PIDCP, art. 2

65 PIDCP, art. 2(3)(a); CIDR, art. 6; CADH, art. 11(3); DUDH, arts. 8 y 12; Convenio 169 oIt, arts. 15(2), 16(4) y 16(5).

66 Por ejemplo: "toda violación de una obligación internacional que haya producido un daño comporta el deber de repararlo adecuadamente... al producirse un hecho ilícito imputable a un Estado, surge de inmediato la responsabilidad internacional de éste por la violación de la norma internacional de que se trata, con el consecuente deber de reparación y de hacer cesar las consecuencias de la violación." Yakye Axa Indigenous Community of the Enxet-Lengua people vs. Paraguay (2002), párr. 179-180.

67

Shelton (2005); International Law Commission (2001). como la Corte Interamericana podría ser el organismo apropiado.

Por tanto, teóricamente sería posible buscar reparación por violaciones de los derechos lingüísticos - por ejemplo, por no proporcionar la educación inicial en la lengua materna o por no utilizar las lenguas indígenas en los medios de comunicación estatales- dado que están especificados en instrumentos internacionales vinculantes y se han producido en el periodo en que el Estado responsable, como parte firmante, tenía la obligación de proteger y respetar. En caso de éxito por parte de los demandantes, también debería ordenarse al Estado prevenir repeticiones de la situación ilícita - de modo que se viera obligado a tomar medidas que no contemplaba antes, como el suministro de servicios de interpretación o de educación bilingüe, facilitación del acceso a los medios de comunicación estatales o la protección de una lengua en peligro-, y conseguir así un resultado benéfico para otras comunidades o individuos, con consecuencias positivas en el futuro. ${ }^{68}$

De otro lado, se podría buscar la reparación por actos $u$ omisiones que no están en sí mismos relacionados con el idioma, sino que tienen consecuencias negativas para él y para los derechos lingüísticos. Retomando el caso colombiano: si el desplazamiento de una comunidad conduce a una dislocación social y cultural que debilite el uso del lenguaje ancestral por las generaciones

68 El requisito de poder atribuir la violación al Estado sería fácil de cumplir cuando se trata de actos de sus organismos y funcionarios, pero también se le podría atribuir en situaciones de contratación oficial de funciones educativas o administrativas a las iglesias, como ocurría en Colombia durante gran parte del siglo XX. 
más jóvenes, las reparaciones podrían abordar este aspecto de daño. Lo mismo puede decirse cuando el daño lingüístico es resultado de violaciones como: no obtener el consentimiento libre, previo e informado para un proyecto de desarrollo que pone en peligro a una comunidad; no ofrecer suficientes servicios públicos de salud o de vivienda, situación que lleva a la muerte de los ancianos que son los hablantes más competentes de una lengua muy debilitada o no proteger a los líderes o activistas involucrados con la revitalización lingüística o con proyectos de educación. El contenido de la orden dependería de las circunstancias, y debería estar conforme con el principio de adecuación reconocido por estándares internacionales. ${ }^{69}$

\section{E. Reparación por pérdida de lenguas como consecuencia de etnocidio}

La Convención para la Prevención y la Sanción del Delito de Genocidio $^{70}$ no tiene tanta aplicación al daño lingüístico como habría sido posible: la definición de "genocidio" en el texto aprobado en 1948 excluyó el concepto de etnocidio o genocidio cultural -que sí figuraba en las versiones anteriores- en favor de las expresiones físicas de genocidio, reteniendo únicamente el traslado forzado de niños de un grupo al otro. ${ }^{71}$ Se ha debatido si esta última forma de genocidio podría

69 Por ejemplo, confirmado en Principios y directrices básicos sobre el derecho de las víctimas de violaciones manifiestas de las normas internacionales de derechos humanos y de violaciones graves del derecho internacional humanitario a interponer recursos y obtener reparaciones, aprobados por la Asamblea General en 2006.

70 Vinculante para Colombia desde su ratificación en 1959

71 Ver Clavero (2008) y Schabas (2000). interpretarse de modo que abarque el caso de los estudiantes indígenas que fueron enviados a internados lejos de sus familias, así como las políticas australianas que dieron lugar a las stolen generations (generaciones robadas) por separar a los niños aborígenes de sus madres y darlos en adopción a familias blancas, con el propósito de cortar sus vínculos con su cultura tradicional, su identidad y su comunidad. Tal transferencia forzada de niños autóctonos por lo general implicaba la pérdida de sus lenguas maternas, debido a la separación de las familias a una edad temprana, perturbando así la transmisión de la lengua, trastorno típicamente reforzado por la prohibición de la utilización de lenguas nativas en internados y otras instituciones.

Skutnabb-Kangas y Dunbar (2010) van más allá y sugieren que la imposición de una educación a un niño en un idioma distinto al de su lengua materna puede constituir por sí misma (incluso cuando el niño se quede viviendo con su familia) un traslado forzoso de un grupo al otro ${ }^{72}$ o "daño a la integridad física o mental de los miembros del grupo", ${ }^{73}$ otro de los cinco brazos de la definición de la mencionada Convención. Si este punto de vista es aceptado, podría decirse que también se ve satisfecho el requisito de la Convención de que haya una intención de "destruir, total o parcialmente, a un grupo nacional, étnico, racial o religioso como tal”; como se mencionó anteriormente, una de las razones

72 Dado, argumentan, que se trata de la debilidad de la lengua materna y de la adquisición de la lengua de un grupo étnico o nacional distinto.

73 Sostienen que tal educación puede dar lugar a deficiencias en el desarrollo lingüístico y, por lo tanto, en el desarrollo intelectual general, que equivale a causar daños mentales a los niños. 
para la imposición de la educación monolingüe en un Estado con población plurilingüe ha sido la creación de una unidad cultural nacional, ya que la pérdida de una lengua puede conducir a la pérdida de la identidad étnica asociada. ${ }^{74}$

Ahora, la DDPI ofrece un aporte para el vacío dejado en 1948 por los negociadores de la mencionada Convención. Consagra el derecho a no ser objeto de genocidio o de violencia, incluyendo la remoción forzada de niños a otro grupo, la asimilación forzada o la destrucción de la cultura. ${ }^{75} \mathrm{~A}$ continuación ${ }^{76}$ requiere que los Estados establezcan mecanismos efectivos para la prevención y el resarcimiento de:

a) Todo acto que tenga por objeto o consecuencia privarlos de su integridad como pueblos distintos o de sus valores culturales o su identidad étnica;

c) Toda forma de traslado forzado de población que tenga por objeto o consecuencia la violación o el menoscabo de cualquiera de sus derechos;

d) Toda forma de asimilación o integración forzada;

La inclusión de "o consecuencia" en el numeral a) de este artículo implicaría que acciones que tienen efectos etnocidas pero carecen de

74 También debe tenerse en cuenta que el art. 3 de la Convención contra el Genocidio también criminaliza los intentos de cometer genocidio y que, además de tener la responsabilidad de enjuiciar a los culpables de actos de genocidio, el propio Estado puede ser el culpable.

75 Art. 7

$76 \quad$ Art. $8(2)$ la intención correspondiente $-\mathrm{y}$ por ende no transgreden la Convención sobre el Genocidiopodrían ser clasificadas como violaciones de la DDPI, y consecuentemente implicar un derecho a reparación.

Otros artículos de la DDPI también consolidan claramente la responsabilidad del Estado de brindar una reparación, lo cual podría aumentar la fuerza de un caso para exigir las reparaciones relacionadas con lo lingüístico, ${ }^{77}$ como haría su homólogo proyecto interamericano una vez acordado. $^{78}$

\section{F. Jurisprudencia orientada a la protección del idioma}

Algunas sentencias de tribunales sobre violaciones de normas internacionales que no precisamente se ocupan de la protección de lenguas o derechos conexos han ordenado medidas de reparación que tienen un componente lingüístico. Esto ha sido más evidente en la jurisprudencia de la Corte IDH que, por ejemplo, en dos sentencias en las que se reconoce la importancia de las lenguas indígenas para informar a las co-

77 Según la DDPI los Estados están obligados a proporcionar reparación por las tierras y recursos (art. 28) y "reparación efectiva de toda lesión de sus derechos individuales y colectivos" (art. 40). Además, el art. 11 los obliga a proporcionar "reparación por medio de mecanismos eficaces, que podrán incluir la restitución, establecidos conjuntamente con los pueblos indígenas, respecto de los bienes culturales, intelectuales, religiosos y espirituales de que hayan sido privados", lo cual parece referirse solamente a objetos materiales, pero tampoco se puede descartar la posibilidad, aunque remota, de una interpretación "evolutiva" que trajera aspectos lingüísticos dentro el alcance de la disposición.

78 Proyecto de Declaración Americana sobre los Derechos de los Pueblos Indígenas, art. XXXIII, el cual enfatiza la importancia de "recursos efectivos e idóneos... para la reparación de toda violación de sus derechos colectivos e individuales". Es uno de los artículos ya aprobados en las negociaciones. 
munidades afectadas de sus derechos, ordenó la radiodifusión, utilizando el idioma nativo, de las partes claves de dichos dictámenes. ${ }^{78}$ Estas sentencias constituyeron un raro ejemplo de la utilización por el Estado de un idioma indígena en el ejercicio de una función pública, y simultáneamente un cumplimiento de sus obligaciones a la luz de los instrumentos internacionales. En el primer caso, la Corte también exigió al Estado suministrar material escolar bilingüe, como parte de un paquete de medidas para mejorar los servicios en la comunidad empobrecida. ${ }^{79}$

La misma Corte fue aún más lejos en 2004 en el caso Masacre Plan de Sánchez vs. Guatemala, en relación con el asesinato de 1.982 aldeanos mayas achí en Guatemala, ya que ordenó:

- Ceremonia oficial de reconocimiento de responsabilidad estatal que debía llevarse a cabo en el idioma nativo achí, además del español;

- Traducción de las dos sentencias de la Corte al achí;

- Publicación de los elementos claves de las sentencias en los dos idiomas: español y achí;

- Promoción por parte del Estado del estudio y conocimiento de la lengua y cultura achí en las comunidades afectadas;

- Dotar a las comunidades con maestros calificados y bilingües.
Dichas órdenes aparentarían ir más allá de la necesidad comunicativa, sirviendo como acciones simbólicas para la reconciliación. Sin embargo, son también formas de poner en práctica los derechos lingüísticos y de fortalecer el uso de una lengua indígena en ámbitos judiciales, administrativos y mediáticos donde históricamente no ha sido usada. Como tal, las órdenes pueden ser vistas como acciones de reparación frente a los daños lingüísticos causados por violaciones de derechos humanos protegidos por la normativa internacional.

El enfoque de la Corte IDH hizo eco recientemente en la decisión T-129/11 de la Corte Constitucional de Colombia, en un caso relacionado con violaciones del derecho a la consulta previa con respecto a tres grandes proyectos de infraestructura. El tribunal concedió el amparo de los derechos alegados y ordenó la publicación parcial de la sentencia en lengua embera-katio, idioma nativo de las comunidades afectadas. ${ }^{80}$ Claramente, la orden fue diseñada dentro de lo simbólico; no obstante, tiene el efecto más amplio de elevar el estatus de una lengua indígena y aplicar los derechos lingüísticos de los hablantes, lo cual, en cierto sentido, es una forma de justicia reparativa lingüística en sí misma.

80 Posteriormente, la misma Corte ordenó la traducción del Auto 173 de 2012 a las lenguas de los Nukak Maku y los Jiw. El Ministerio de Cultura organizó y entregó las traducciones en los siguientes meses. 


\section{IV. ¿EN QUÉ PUEDE CONSISTIR LA JUS- TICIA REPARATIVA LINGÜÍSTICA?}

\section{A. Enfoques reparativos aplicables al daño lingüístico}

El análisis precedente trató de plantear la posibilidad de que, en un futuro próximo, un pueblo indígena pueda tener éxito con una demanda de reparación, ya sea en un tribunal nacional o internacional, por daños lingüísticos causados por la violación por parte del Estado de alguna de las obligaciones internacionales. Sin importar la naturaleza del derecho violado, si resultara en daños lingüísticos identificables, un Estado podría encontrarse enfrentando una orden ${ }^{81}$ de implementar el tipo de medidas abogadas en las últimas décadas por los órganos de la onu, los expertos en idiomas amenazados, los activistas de derechos de grupos minoritarios y los líderes indígenas.

Esta sección examinará en breve qué medidas podrían aplicarse. Al hacerlo, también se dejará abierta la posibilidad de que tales determinaciones sean adoptadas voluntariamente por un Estado, sin estar obligado por una sentencia judicial. De manera semejante, un Estado podría desarrollar un programa de justicia reparativa lingüística sobre la base de la obligación moral de hacer frente a las injusticias del pasado, y no solo las obligaciones legales adquiridas desde 1948.

81 Por supuesto, si dicha orden se emite por un órgano internacional, puede que el Estado no se considere vinculado o decida no aplicarla.
Se suele clasificar las reparaciones en cuatro formas: restitución, indemnización o compensación, rehabilitación y satisfacción. ${ }^{82}$ La experiencia de reparaciones, en la práctica, nos ofrece poca orientación precisa con respecto a la forma de remediar un daño como el lingüístico: al parecer, hasta la fecha todos los casos de reparación por una pérdida de índole cultural han correspondido a objetos tangibles y no de patrimonio inmaterial, como de facto lo es el idioma. ${ }^{83}$ En esos casos se restituye el objeto, o si ha sido destruido, robado o perdido se paga una compensación, pero la restitución es la prioridad. Del mismo modo, en el contexto de reparaciones de tierra a las comunidades indígenas desplazadas es ampliamente aceptado el principio según el cual la importancia de la tierra para la integridad cultural de los pueblos indígenas requiere que la restitución de la tierra original sea el objetivo prioritario.

A sabiendas de que el idioma también juega un papel de trascendencia en la integridad cultural, podemos importar el principio aplicado a las tierras indígenas y, a la vez, por analogía, la práctica con respecto al patrimonio intangible. ¿Pero cómo se puede hablar de restitución de cosas tan inmateriales y variables como las

82 Categorización utilizada en el artículo 25 de la Ley 1448 de 2011. En Greiff (2006) se resumen como: a) La restitución -medidas para restablecer las víctimas a su situación anterior-; b) indemnización cuantificación de los daños, incluidos los daños económicos, físicos y mentales-; c) rehabilitación -prestación de atención social, médica y psicológica-; d) satisfacción (y garantías de no repetición) -incluyendo disculpas oficiales y la revelación de la verdad, el retorno de los restos mortales, el castigo de los culpables y la reforma institucional-.

83 Generalmente elementos en poder de museos o universidades, por ejemplo, objetos ceremoniales, restos humanos, piezas arqueológicas. Véase, Vrdoljak (2008). 
lenguas y las prácticas lingüísticas? Cuando el daño en cuestión es de carácter cultural, resulta difícil dar marcha atrás dos, cuatro o cinco siglos, dada la existencia transformada de las comunidades indígenas. Sin embargo, en el caso de daños lingüísticos, sería posible hablar de la restitución como forma arquetípica de reparación, incluso cuando no se pretende devolver el monopolio que una lengua alguna vez tuvo en la comunidad a que pertenece. La restitución en el sentido lingüístico incluiría casos donde las diversas interacciones y funciones se comparten o se dividen con la lengua del Estado; asimismo, el idioma tradicional podría recuperar su importancia solamente en ciertos ámbitos trascendentes como el religioso y para festividades importantes. La forma (y también el éxito) de la restitución dependería del grado de vitalidad del idioma y de otras circunstancias sociolingüísticas, además - de acuerdo con los principios bien establecidos por la normativa internacional- de la decisión de la comunidad en cuestión. Conceptualizada de este modo, la justicia reparativa lingüística siempre se podría implementar por la opción de la restitución, sin necesidad de recurrir a la compensación. Asimismo, concordaría con lo que ha señalado Anaya (2004) con respecto al derecho de los pueblos indígenas a la autodeterminación, es decir, las acciones para remediar violaciones históricas no implican necesariamente un retorno al statu quo anterior, sino, más bien, se desarrollarán de acuerdo con las aspiraciones actuales de los grupos agraviados.

\section{B. Panorama de acciones estatales de posible carácter reparativo}

Hasta la fecha no ha ocurrido una reparación sensu stricto para daño lingüístico causado por los diversos procesos coloniales, es decir, una sola acción integrada estatal que combine el reconocimiento de una injusticia histórica con la implementación de medidas dirigidas a las lenguas y prácticas lingüísticas perjudicadas por la injusticia en cuestión. Sin embargo, hay ejemplos de Estados que han emitido una disculpa en un momento, y en otra ocasión han anunciado medidas orientadas a reparar las lenguas afectadas, sin vincular las dos distintas respuestas explícitamente. Esos ejemplos de dimensiones independientes (disculpa separada de remedio) se pueden examinar como si se hubieran dado juntas, para poder contribuir a una idea del contenido de una justicia reparativa lingüística.

El caso noruego es el que más se aproxima a la definición de reparación. En 1997 su Rey ofreció una disculpa estatal al pueblo sami por políticas asimilacionistas y otras injusticias del pasado, seguida por la creación de un fondo de compensación para sus comunidades, que incluyó apoyo para programas sobre lengua y cultura. Suecia y Finlandia han adoptado programas similares, aunque solo el primero dio una disculpa clara. ${ }^{84}$

84 Cada uno de los tres países tiene ahora un Parlamento Sami, con responsabilidades en temas culturales, en particular. El otro Estado con poblaciones Sami, Rusia, no ha seguido el ejemplo de sus vecinos. 
En Canadá el Estado ofreció disculpas y se entregó una compensación, pero sin conexión con las acciones emprendidas en materia cultural o lingüística. El caso más conocido fue un litigio de grupo interpuesto por personas que habían sufrido el sistema de internados que trataba de asimilar los niños nativos, establecimientos tipificados por prohibiciones en el uso de las lenguas aborígenes y por tasas de mortalidad muy elevadas, además de numerosos casos de abuso que dieron lugar a daños físicos y psicológicos en el largo plazo. Se acordó un paquete a título de compensación en $2006,{ }^{85}$ seguido en 2008 por una disculpa formal por parte del Primer Ministro y el establecimiento de una Comisión de Verdad y Reconciliación. Aunque la pérdida de la cultura y la lengua fue inmensa, el paquete de compensación no incluyó programas relacionados con el idioma. Sin embargo, independientemente ya se habían aplicado varias medidas en favor de las lenguas aborígenes, con una importante financiación asignada en las últimas décadas por los diversos gobiernos de la federación canadiense. ${ }^{86}$

De modo parecido, en el Congreso estadounidense se emitió una resolución de disculpa a los

85 Lo que implicó pagos individuales a todos los antiguos alumnos y más de 200 millones de dólares canadienses dedicados al resarcimiento, la reconciliación y la conmemoración.

86 Parte de este apoyo se hizo en respuesta al informe de 1996 de la Comisión Real sobre Pueblos Aborígenes (asimismo el pago de compensación a comunidades de inuit que habían sido obligatoriamente relocalizadas en los años 50 ), pero la mayoría de sus recomendaciones no fueron implementadas. Cabe mencionar que en el norte de Canadá, el territorio de Nunavut (creado en 1999 para dar un grado de autogobierno a los inuit o esquimales) hizo de inuktikut una lengua de la administración junto con el inglés y el francés; además, ha habido una importante financiación federal para la Inuit Broadcasting Corporation a partir de 1983 . hawaianos en $1993^{87}$ y otra para los indígenas norteamericanos en 2009,88 pero sin acompañarlas con medida alguna, y enfatizando que no implicaban responsabilidad de devolver tierras o pagar compensación. Sin embargo, la misma institución aprobó la Native American Languages Act de 1990, el primer esfuerzo legislativo a nivel nacional en las Américas dirigido a los idiomas indígenas, seguida por la Esther Martinez Native American Languages Preservation Act de 2006, lo que ha financiado el desarrollo de formas de aprendizaje de inmersión lingüística iniciadas por las comunidades.

A pesar de la amenaza inminente a sus numerosos idiomas, Australia no es un modelo en este campo. ${ }^{89}$ En 1997, una comisión oficial sobre las "generaciones robadas" 90 publicó un infor-

87 En ella se reconoce que el derrocamiento del Reino de Hawai un siglo antes fue impulsado por estadounidenses sin que los hawaianos renunciaran a la soberanía sobre sus tierras.

88 Reconociendo la larga historia de depredaciones oficiales, políticas mal concebidas, incumplimiento de tratados y muchos casos de violencia, maltrato y negligencia.

89 Vale recordar que no reconoció la ciudadanía de sus habitantes indígenas sino hasta 1967, les ha dado poco control de las escuelas (aunque con uso limitado de lenguas nativas en algunas zonas), tardó en reconocerles derechos sobre la tierra, y les da un nivel de autogobierno mínimo. Mientras que otros territorios colonizados por los británicos se caracterizaron por la falta de respeto por los tratados concertados con sus pueblos autóctonos, en Australia no se hizo ningún tratado que pudiera romperse. De hecho, hasta que se produjo una decisión de la Corte Superior en 1992 el sistema de derecho se basaba en el principio de terra nullius, bajo la ficción de que no existía ningún sistema de derecho en el momento de la colonización.

90 Es decir, los niños arrebatados por la fuerza a sus padres y entregados a familias blancas o a instituciones públicas y privadas, práctica que comenzó en el siglo XIX y que en algunos casos continuó hasta la década de los sesenta. De la misma forma que en los internados norteamericanos, además de maltrato físico y trauma psicológico, esa práctica se tradujo en niños que crecieron sin conocimiento de su cultura y lengua tradicionales. Conducta a todas luces violatoria de las contemporáneas normas de derechos humanos, y probablemente de la Convención para la Prevención y la Sanción del Delito de Genocidio. 
me con considerables referencias a la pérdida cultural y lingüística sufrida. ${ }^{91}$ Se recomendó reparar las personas "robadas", pero no se ha creado ningún programa de compensación, salvo un sistema legislado en 2006 en Tasmania, el estado con la población indígena más pequeña. Algunos individuos trataron de obtener una indemnización por medio de litigio, pero solo uno ha tenido éxito, ya que los jueces concluyeron que la práctica, aunque violatoria de los estándares actuales, era conforme con las leyes de la época en cuestión. La principal recomendación implementada ha sido la emisión de disculpas o declaraciones de arrepentimiento por los jefes de los varios gobiernos, y no ha habido ningún plan para reparar la pérdida cultural sufrida. Pero la atención al tema motivó a diversos estados y territorios a introducir políticas relativas a los idiomas indígenas desde 2004, y por fin en 2008 se puso en marcha una política nacional ${ }^{92}$ que propuso un enfoque coordinado y con una mirada que abarca diversos ámbitos sociales y no solamente el sistema educativo. La nueva política reconoce el hecho histórico de debilitamiento y desaparición de las lenguas como resultado de la colonización. ${ }^{93}$ Así mismo,

91 National Inquiry into the Separation of Aboriginal and Torres Strait Islander Children from Their Families (1997).

92 Nótese que es una política, no una legislación

93 De las por lo menos 250 lenguas habladas al comienzo de la conquista británica en 1788, más de 100 se han extinguido ya. Nettle y Romaine (2000, p. 9) creen que Australia puede constituir el caso más extremo de devastación de la diversidad lingüística de los últimos siglos. Según AIATSIS (2005) y Australian Human Rights Commission (2009), solo 18 lenguas tienen hablantes en todas las generaciones, entonces la gran mayoría son "moribundas". Ninguna tiene más de 4.000 hablantes, y las crecientes presiones para asimilarse a las formas de vida de la sociedad dominante llevan hacia el inglés o dos creoles de base inglés que son ampliamente utilizados en el norte del país. la necesidad de apoyo gubernamental y, de hecho, presentó la atención a las lenguas como parte de un esfuerzo mucho más amplio para “cerrar la brecha" entre los indígenas y los australianos no indígenas con respecto a una gama de indicadores sociales y económicos.

Nueva Zelanda lidera los países de asentamiento británico en cuanto a su atención a su cultura indígena. Una ley de 1987 declaró la cooficialidad del idioma maorí y creó una comisión especial para él. ${ }^{94} \mathrm{~A}$ raíz de dicha ley hubo una expansión de la radiodifusión en lengua maorí y la financiación de programas de enseñanza. Los pasaportes se encuentran entre los documentos oficiales bilingües (inglés y maorí), al igual que gran parte de la señalización en edificios públicos. Parte de la financiación ha sido asignada a "nidos de lenguas", espacios donde los niños de edad preescolar reciben educación de inmersión en el idioma tradicional. ${ }^{95}$

Los casos de Noruega y Nueva Zelanda tal vez podrían considerarse como ejemplos de una práctica estatal incipiente en cuanto a reconocer y pedir disculpas por ciertas injusticias cometidas en el pasado, mientras se intenta re-

94 Se trata de la Maori Language Act 1987, la cual vino después de una orden del Tribunal de Waitangi, el organismo creado para examinar los reclamos presentados en el marco del Tratado de Waitangi celebrado en 1840 entre los colonos británicos y algunos líderes Maori, en su sentencia en un caso respecto de las implicaciones del Tratado para la lengua nativa. Desde los 80 del siglo pasado se ha destacado por su énfasis en cumplir los términos del Tratado, anteriormente ignorado. Véase por ejemplo May (2012).

95 El primer nido de lenguas se estableció en 1982, lo cual condujo a la difusión de iniciativas de educación primaria y luego secundaria empleando el maorí. Pronto el concepto fue adoptado por activistas para la lengua hawaiiana, y más recientemente por comunidades en EE. UU., México y Australia. 
mediar los daños lingüísticos que han resultado del patrón de iniquidades entero. Se trata de medidas que podrían ser aportes a un enfoque estatal que pretendería aplicar una justicia reparativa respecto al daño causado a los derechos, conocimientos y prácticas lingüísticos por los procesos de conquista y colonización.

\section{Otros elementos aptos para la justicia reparativa de la lengua}

Hay, además, varios ejemplos de políticas en diversas partes del mundo enfocadas en el apoyo a lenguas indígenas o minoritarias por parte de actores estatales y no estatales. Un conjunto de modelos se constituye por territorios donde se ha reafirmado la posición de un idioma que previamente era subordinado a la lengua de los grupos dominantes dentro de un Estado multiétnico. Quebec, Cataluña y el País Vasco se destacan por esfuerzos constantes desde la década de 1970 para elevar el estatus de la lengua local y reducir la hegemonía percibida de la lengua mayoritaria del Estado o del gobierno central. Otras orientaciones se ven en países donde las lenguas locales fueron subordinadas a la lengua de la antigua potencia colonial, pero la independencia se tradujo en esfuerzos para revertir la situación. ${ }^{96}$ Las medidas adoptadas en estos lugares para elevar la posición de la respectiva lengua subordinada (LS) han incluido:

- Proveer servicios y documentos de la administración pública en la ts.

96 Ejemplos de ello son el swahili, el malayo, el cingalés y el hindi, todos ante el inglés.
- Exigir que los funcionarios aprueben pruebas de competencia en la ss.

- Usar la ss como medio de instrucción por lo menos en una parte de la educación.

- Establecer universidades que utilicen la ss y cursos de aprendizaje para adultos.

- Usar la ts en la señalización pública y fomentar su uso en el ámbito privado.

- Promover la publicación, el uso literario y la presencia de la ss en la radio y la televisión pública.

- Establecer una academia del idioma para construir el corpus de la Ls, lo que le permite ser utilizada en funciones para las que anteriormente se carecía de terminología.

- Crear programas de acción afirmativa en favor de la Ls o de sus usuarios. ${ }^{97}$

Otras medidas se pueden tomar de programas para apoyar o revitalizar lenguas que no están en condiciones de hacerse dominantes a nivel nacional ni subnacional, pero tendrían que incluir la mayoría de las lenguas amenazadas e indígenas. Algunas de estas ya se aplican como parte de los esfuerzos que se realizan en las comunidades indígenas, y siguen las recomendaciones de expertos lingüistas $y$ educadores como Grenoble y Whaley (2006), Tsunoda (2005), Hornberger y King (1996) y Fishman (1991):

97 Como lo ha señalado el Comité de Derechos Humanos (1989), el principio de igualdad a veces requiere que los Estados partes del PDDCP tomen "disposiciones positivas para reducir o eliminar las condiciones que originan o facilitan que se perpetúe la discriminación". 
- Invertir en la formación adecuada de maestros de escuela hablantes de ss (preferentemente con us como medio de instrucción), y proporcionar suficientes materiales escolares en Ls.

- Establecer entornos en los que los adultos con fluidez en la ss den educación de inmersión a los niños.

- Aumentar la cantidad de material impreso disponible en la ss y promover su investigación.

- Facilitar la presencia de la ss en radio, televisión e internet, así como proporcionar equipamiento y formación a hablantes de ss para tales propósitos.

- Capacitar intérpretes y traductores en la LS para la provisión de servicios públicos.

- Aumentar la conciencia entre los adultos de la necesidad de utilizar la ss en la crianza de sus hijos si quieren mantener su lengua viva.

- Incluir clases sobre la ss y la cultura de sus hablantes como componente de la educación de los miembros de la mayoría. ${ }^{98}$

- Promover actividades en que la ts se utiliza y usarla en la toponimia local. ${ }^{99}$
La mayoría de tales medidas produciría un involucramiento e incluso un empoderamiento de los mismos hablantes del idioma. En el caso de lenguas indígenas esta consecuencia coincidiría con objetivos de justicia social en los que se enfatiza que las lenguas -y los derechos conexos- pertenecen a los pueblos. ${ }^{100}$

Sin embargo, algunas de estas medidas confrontan a los miembros de la mayoría y los comprometen a hacer algo en relación con la lengua históricamente subordinada. Por ejemplo, cuando un mínimo de conocimiento de ese idioma se convierte en un requisito para las convocatorias a cargos de la administración pública. Aunque ese tipo de política ha encontrado oposición cuando se ha impuesto, como en el País Vasco, se puede justificar no solo porque estimularía el uso de la lengua previamente subordinada, sino también porque es una forma de corregir el multilingüismo asimétrico que caracteriza a estas sociedades. Como sostiene Pou Giménez (2011): mientras las minorías normalmente hacen todas las concesiones y adaptaciones, puede parecer razonable -sin mencionar justo- cargar la mayoría con la responsabilidad de invertir sus esfuerzos en el aprendizaje de la lengua indígena o minoritaria. ${ }^{101}$

100 Lo cual muestra la importancia de formar miembros de las comunidades para poder liderar sus propios esfuerzos respecto de las lenguas. Un ejemplo colombiano: de los 47 egresados de la maestría en Etnolingüística que ofrecía el Centro Colombiano de Estudios de Lenguas Aborígenes (CCELA) con la Universidad de los Andes, 12 pertenecían a comunidades indígenas o palenqueras. Capacitados de este modo, pudieron ayudar a sus comunidades en el desarrollo de programas etnoeducativos. (Enciso Patiño, 2004; Aguirre Licht, 2004).

101 La discriminación que puede surgir en ausencia de una intermediación lingüística fiable se demostró en 2011 por la revelación del documental Nacidos el 31 de diciembre, de Priscila Padilla, a su vez basado en el libro Manifiesta no saber firmar, de Estercilia Simanca Pushaina. 
Las anteriores son solo algunas de la amplia gama de acciones que se han intentado con el fin de proteger y promover las lenguas indígenas puestas en condición de inferioridad, así como de garantizar los derechos lingüísticos de los hablantes. La idoneidad de cada acción dependería de las circunstancias, tales como los recursos de que disponen los gobiernos, el número y ubicación de los hablantes, la vitalidad de la lengua y una serie de características sociales y económicas. Lo más importante es que la comunidad a la que pertenece la lengua participe en la elección del enfoque que se adopte y este compagine con su voluntad. Una imposición desde arriba, o sea, desde el Estado o la sociedad mayoritaria, iría en contra de los objetivos de una verdadera justicia reparativa, sin mencionar los principios establecidos en la normativa internacional sobre los derechos indígenas.

\section{EL CASO COLOMBIANO: POSIBILI- DADES DE JUSTICIA REPARATIVA LINGÜÍSTICA}

\section{A. Lo que está en juego: la diversidad lingüística de Colombia}

Colombia es un país de diversidad lingüística significativa en un sentido amplio, es decir, tanto en variedad como en multiplicidad. Las 65 lenguas indígenas sobrevivientes pertenecen,

En él se presenta la situación de miles de personas de la etnia wayúu, que siendo analfabetas o con conocimiento mínimo del español, se enteraron de que sus nombres habían sido escritos de forma incorrecta, y en algunos casos ofensiva, por parte de funcionarios del registro civil, claramente en violación de la CIRD y el Convenio 169 оाт. Inicialmente la oficina de registro iba a cobrar por hacer las correcciones, hasta que la atención mediática lo condujo a ofrecer una rectificación gratuita. se cree, a 13 familias lingüísticas diferentes, además de 8 "lenguas aisladas" ${ }^{102}$, lo que significa que se puede hablar de 21 puntos distintos de origen. En contraste, si bien hay docenas de lenguas en el continente de Europa, casi todas pertenecen a solo dos familias. ${ }^{103}$ Del mismo modo, otros países con un gran número de idiomas, como India o Nigeria, tienen un número de familias lingüísticas menor que Colombia. La diversidad colombiana es aún mayor cuando se incluyen los idiomas creoles palenquero y raizal, frutos del encuentro de lenguas europeas con diversos idiomas africanos.

La desintegración sufrida por las lenguas nativas colombianas desde la fundación de Santa Marta en 1526 fue inmensa. La mayoría de los idiomas de las principales áreas de asentamiento en el Caribe y en las zonas andinas dejaron de ser habladas en los primeros siglos de la colonización. ${ }^{104}$ Algunos pueblos indígenas tan numerosos como los Pastos, Zenus y Pijaos perdieron completamente el uso de su lengua ancestral antes del siglo XX.

Entre las lenguas que sobreviven, algunas se consideran moribundas, es decir, solo son habladas por personas de edad avanzada y no se enseñan a los niños. En ausencia de un esfuerzo serio para sumergir a los niños en el idioma ancestral, este dejaría de ser hablado con la

102 O sea, idiomas que parecen carecer de parientes por completo.

103 Véase Gafner-Rojas (2008). Una excepción es el euskera (vasco), un idioma aislado.

104 Véase, por ejemplo, Pineda Camacho (2000) y Triana y Antorveza (1987). 
muerte de la generación mayor, dentro de unas pocas décadas. Otros idiomas colombianos todavía son hablados por adultos jóvenes, pero tienen escaso conocimiento entre los niños, lo que implica que estos también son vulnerables. ${ }^{105}$ Cabe mencionar que alrededor de la mitad de las 65 lenguas indígenas colombianas tienen menos de 1.000 hablantes, lo cual es otra forma de vulnerabilidad, especialmente si les toca un desastre o conflicto.

Esta situación de riesgo inmediato de algunas lenguas y de vulnerabilidad en el mediano plazo de otras se repite donde quiera que haya habido colonización de pueblos indígenas. Australia y los Estados Unidos están peor en cuanto a extinción de lenguas indígenas. Sin embargo, Colombia tiene una particularidad que la distingue de las mencionadas naciones y de la mayor parte de América Latina: muchos de sus pueblos indígenas están atrapados en el conflicto armado contemporáneo. Entre las muchas consecuencias negativas sociales y culturales de este, está el desplazamiento de familias y comunidades indígenas, y en cada asesinato de un anciano o líder se encuentra el debilitamiento de las prácticas lingüísticas tradicionales.

\section{B. Un posible marco para la justicia reparativa lingüística en Colombia}

En este artículo no hay espacio para analizar el grado de cumplimiento de Colombia con las

105 Según lo revelado por el Ministerio de Cultura, específicamente en el Autodiagnóstico sociolingüístico del Programa de Protección a la Diversidad Etnolingüística (PPDE). La lengua palenquera se encuentra en esta categoría. obligaciones internacionales adquiridas durante las últimas seis décadas y media, aunque se podría suponer que en muchos aspectos se ha quedado corto. ${ }^{106}$ Sin embargo, vale notar que ha sido líder en su aceptación de los principios del Convenio 169 oIT $^{107}$ y en inscribir el reconocimiento de las lenguas nativas en su Constitución, una medida simbólica que puede tener implicaciones favorables para la situación real de las lenguas. ${ }^{108}$

La promulgación de la Ley de Lenguas Nativas o Ley 1381 de 2010 significa que Colombia tiene, como algunos de sus vecinos, ${ }^{109}$ un marco apto

106 Por ejemplo, es importante notar que las formas de respuesta estatal a las demandas relacionadas con las lenguas indígenas se han dado principalmente en el ámbito de la educación, con amplia aceptación del concepto de etnoeducación y del principio de participación comunitaria. Sin embargo, ha habido mucha crítica sobre la eficacidad de la elaboración y especialmente sobre la implementación de tales programas. Como lo ha señalado De Mejía y Montes Rodríguez (2008), la atención y el financiamiento dados a las lenguas indígenas en las escuelas colombianas es muy inferior a lo asignado a la enseñanza de los idiomas europeos en los colegios de la élite, especialmente el inglés.

107 En cambio, Canadá, EE. UU., Australia y Nueva Zelanda nunca han sido Estados partes de los Convenios 107 y 169 de la оाт, y fueron los únicos que se negaron a aceptar la DDPI (ya han cambiado esa postura). Como ya se mencionó, Nueva Zelanda tiene un alto reconocimiento del idioma maorí, pero ninguna de las tres grandes federaciones tiene disposiciones constitucionales que reconozcan la presencia indígena milenaria, los derechos indígenas, las lenguas y las culturas aborígenes. Son prósperos y libres de conflicto interno, pero no han aprovechado estas ventajas para apoyar sus idiomas indígenas como podrían haberlo hecho.

108 Sirviendo de ejemplo para otros países latinoamericanos, que en los años posteriores incorporaron pronunciamientos semejantes en su Carta Magna. En la Constitución de Bolivia de 2009 este reconocimiento se elevó más allá de lo simbólico al crear la obligación de emplear las lenguas nativas en las funciones gubernamentales.

109 Desde 2003 se ha aprobado legislación orientada a la protección lingüística en México, Perú, Guatemala, Venezuela, Paraguay y Panamá. Claramente, existe el riesgo de que estas legislaciones sean simbólicas, es decir, que no sean aplicadas. Sin embargo, ha habido algo de implementación, por ejemplo, la ley mexicana condujo a la creación del INALI (Instituto Nacional de Lenguas Indígenas), que ha recogido información sociolingüística sobre los más de 100 idiomas del país. Por lo general, las acciones concretas quedan por hacerse. 
para la acción estatal, orientado a proporcionar un cierto grado de justicia reparativa lingüística a los hablantes de lenguas indígenas y creoles. ${ }^{110}$ La nueva legislación proclama en su título que pretende desarrollar los artículos 7, 8, 10 y 70 de la Constitución y los artículos $4^{\circ}, 5^{\circ}$ y 28 del Convenio 169 ort, además de mostrar en su contenido que está en consonancia con las disposiciones de la DDPI que tocan el tema de las lenguas, como también con otros textos emitidos por órganos internacionales.

Por ejemplo, la Ley otorga al hablante de una lengua indígena el derecho a usarla en su trato con el sistema de justicia, la administración pública y los servicios de salud, mientras se espera que las entidades avancen en adquirir la capacidad de proporcionar servicios de interpretación. ${ }^{111} \mathrm{El}$ cumplimiento de estas disposiciones garantiza los derechos de las personas con limitado conocimiento del español, pero también representa un gesto simbólico importante, al declarar estos idiomas dignos de ser usados en las operaciones propias del Estado. Esta importancia se ve reforzada por la exigencia a las entidades competentes de la administración pública de utilizar las lenguas nativas, en diversos medios, para difundir las leyes, los reglamentos y los contenidos de los programas dirigidos a grupos étnicos. ${ }^{112}$

110 Abarca también el romaní, hablado por la población rom (gitanos).

111 Ley 1381 , arts. 7,8 y 9.

112 Ley 1381 , art. 8.
En el Título III: Protección de lenguas nativas, obliga al Estado a diseñar y llevar a cabo programas para revitalizar y fortalecer las lenguas en estado de precariedad y dispone que los planes nacionales y regionales de desarrollo deben asignar recursos para esos fines. ${ }^{113}$ Además, los ministerios y otros organismos estatales ${ }^{114}$ deben fomentar o apoyar: ${ }^{115}$

- La producción de programas mediáticos y materiales impresos, de audio, audiovisuales y digitales en lenguas nativas, y la formación de hablantes en la producción de tales materiales, asimismo la facilitación de acceso a los nuevos medios y tecnologías de comunicación.

- La conservación y la difusión de materiales en lenguas nativas en las bibliotecas, los centros culturales y archivos.

- Proyectos para la investigación y documentación de las lenguas nativas.

- El establecimiento de programas de capacitación en el conocimiento y uso de lenguas nativas a personas no indígenas responsables por la prestación de servicios públicos o desarrollo de programas para comunidades con dificultades para comunicarse en español.

- La creación de cursos de estudio de lenguas nativas y de programas de formación de investigadores ${ }^{116}$, traductores e intérpretes.

113 Ley 1381 , arts. 10, 12 y 13. También puede dar apoyo a los programas para recuperar idiomas extintos (art. 14). Incluyendo los distintos niveles de gobierno e instituciones educativas y culturales, en colaboración con entidades privadas.

115 Ley 1381 , arts. $16,17,18,19$ y 21.

116 Con especial apoyo a integrantes de las comunidades nativas. 
En relación con el sistema educativo la Ley dispone que en las escuelas y en las comunidades donde se hable una lengua nativa se garantice que su enseñanza sea obligatoria y, además, que el Estado realice las gestiones necesarias para asegurar que todos los educadores la hablen, la escriban y conozcan la cultura del grupo.

Esta Ley también prevé la repetición, cada cinco años, de un autodiagnóstico sociolingüístico. El primer autodiagnóstico se inició en 2009 con la colaboración de expertos del País Vasco, región autónoma de España que se destaca a nivel mundial por su experiencia en la revitalización lingüística. ${ }^{117}$ Contó con un alto nivel de participación de integrantes de las propias comunidades étnicas en su ejecución, especialmente etnoeducadores y otros interesados en la protección de lenguas tradicionales. En cada comunidad encuestada se seleccionó un coordinador local, según criterios que incluyeron su competencia en el idioma respectivo; también los encuestadores fueron miembros de la comunidad. Las encuestas se tradujeron a las lenguas en cuestión, proceso que fue realizado principalmente por los propios hablantes. Con la aplicación de la encuesta se esperaba, además de proporcionar información sobre las acciones del Ministerio de Cultura y otros órganos del Estado, crear conciencia en las comunidades sobre los riesgos para la supervivencia de su lengua y la necesidad de adoptar medidas preventivas o paliativas.

117 Junto con Cataluña, el País Vasco se considera líder en buenas prácticas de revitalización lingüística. Véase, por ejemplo, Gorter y Cenoz (2012).
Un elemento muy importante en lo dispuesto por la Ley en comento es la creación del Consejo Nacional Asesor de Lenguas Nativas, encargado de formular diversas recomendaciones sobre las acciones estatales pertinentes. Sus funciones incluyen la asesoría al Ministerio de Cultura en la preparación del Plan Nacional Decenal de Protección y Fortalecimiento de las Lenguas Nativas. Igualmente, ordena que la mayoría de los consejeros pertenezcan a las comunidades interesadas y sean elegidos por ellas, lo cual aumenta la probabilidad de que las decisiones del Consejo reflejen las prioridades de estas y no las preferencias de la sociedad mayoritaria. A esto se suma el énfasis repetido en la Ley de que las decisiones y acciones autorizadas por ella se hagan en estrecha concertación con las comunidades de lenguas nativas. Cabe mencionar que el proyecto de ley fue presentado al Congreso por la ministra de Cultura, pero en su redacción contó con la participación significativa de miembros de grupos étnicos, y reuniones con las comunidades y organizaciones de todo el país para obtener su aprobación para el documento.

Las disposiciones legales también promueven el diseño de planes conjuntos con los Estados vecinos, ${ }^{118}$ lo cual es esencial si se pretende hacer un esfuerzo serio para apoyar a las numerosas comunidades lingüísticas con una distribución binacional o incluso trinacional, ${ }^{119}$

\footnotetext{
118 Ley 1381 , art. 15.

119 Los siguientes pueblos se extienden tras las fronteras colombianas: Wayúu, Yukpa, Piapoco, Sikuani, Piaroa, Puinave, Achagua, Barí, Yaruro/Pume, Baniva (Venezuela); Awá y Kofán (Ecuador); Kunatule, Waunany Embera (Panamá); Siriano, Cubeo, Desano, Guanano, Ca-
} 
sin mencionar el debido cumplimiento de las responsabilidades impuestas por la normativa internacional. ${ }^{120}$

\section{Necesidad de implementación y coherencia}

Utta von Gleich, experta en educación intercultural bilingüe y colaboradora de la Unesco y otras instituciones, ha recomendado la Ley 1381 de Colombia como un nuevo modelo para el continente por haber delineado claramente los ámbitos de responsabilidad e implementación; por abarcar tanto la conservación como la modernización de las lenguas indígenas; y por ser un instrumento creado de forma participativa que combina enfoques en dos direcciones: de arriba hacia abajo y de abajo hacia arriba (von Gleich, 2010).

Sin embargo, hay que enfatizar que la Ley 1381 es solo un punto de partida, ya que no proporciona los detalles sobre cómo, cuándo y con qué fondos los órganos estatales van a cumplir con sus obligaciones. Se aprecian mínimas referencias a esta ley en el Plan Nacional de Desarrollo 2010-2014, a pesar de que una inclusión adecuada habría permitido avanzar con los proyectos de revitalización lingüística y de otra índo-

rapana, Bara, Piratapuyo, Pisamira/Papiwa, Tuyuca, Tukano (Brasil); Bora, Ocaina, Yagua (Perú); Tikuna, Cocama, Uitoto (Brasil y Perú); Curripaco y hablantes de Geral o Nheengatú (Brasil y Venezuela).

120 Por ejemplo, en el PIDESc, art. 23. Véase también CDESC, Observación 19, párr. 57, el cual urge recurrir a acuerdos internacionales para hacer efectivo el derecho a participar en la vida cultural. Más recientemente, en 2013, Colombia se comprometió, al ratificar la Convención sobre la Protección y Promoción de la Diversidad de las Expresiones Culturales, a procurar colaborar a nivel internacional para facilitar la protección de la diversidad cultural, con referencia especial a las expresiones culturales amenazadas. le previstos en la legislación. El Plan Nacional Decenal de Protección y Fortalecimiento de las Lenguas Nativas todavía no se ha producido, aunque el plazo límite de dos años fijado por la Ley se cumplió el 25 de enero 2012. El Consejo Nacional Asesor de Lenguas Nativas, que debía orientar al Ministerio de Cultura en la elaboración del Plan Nacional Decenal, solo comenzó a reunirse en abril de $2013,{ }^{121}$ y ya que ha sido convocado, mucho dependerá de cómo proceda en su misión de definir, en concertación con las comunidades afectadas, las medidas más apropiadas para revitalizar los idiomas de los grupos étnicos colombianos, y así dar otro paso hacia una forma de justicia reparativa para las lenguas. Por supuesto, lo esencial será un compromiso genuino por parte del Estado (empezando pero no terminando en el Ministerio de Cultura) de proveer los recursos necesarios para poner en práctica las propuestas que desarrolle el Consejo y las comunidades y hacer de la atención a las lenguas una prioridad en su agenda, comenzando por asignar recursos en el Plan Nacional de Desarrollo 2014-2018 y la búsqueda de colaboración internacional. Además, haría falta una fuerte cooperación con el Ministerio de Educación y otros ministerios y organismos públicos pertinentes, dado el carácter polifacético de las cuestiones lingüísticas indígenas.

Otra oportunidad perdida para ampliar parcialmente la base legislativa de carácter reparativo a favor de las lenguas indígenas se produjo con la promulgación del Decreto-Ley 4633 de 2011,

121 Solo hasta mayo de 2012 se decretó la reglamentación que determina su composición, esto es, cinco meses después del plazo estipulado en la legislación. 
por el cual se dictaron "medidas de asistencia, atención, reparación integral y de restitución de derechos territoriales a las víctimas pertenecientes a los Pueblos y Comunidades indígenas". Dicho Decreto contiene referencias a la utilización de traductores e intérpretes en lenguas indígenas (y una cita de la Ley 1381), y sus numerosas declaraciones sobre lo transcendental de la integridad cultural y las prácticas tradicionales son también importantes. Sin embargo, queda la inquietud sobre si habría sido posible decretar más explícita y ampliamente algunas medidas reparativas orientadas a apoyar las lenguas indígenas y los derechos de sus hablantes, así como a establecer mecanismos para aplicar tales medidas. ${ }^{122}$

También el gobierno colombiano podría considerar la posibilidad de abordar y remediar parcialmente otros daños infligidos a los pueblos indígenas en el transcurso del conflicto armado, o incluso de otros problemas del país, a través de medidas orientadas a apoyar las lenguas y los derechos de sus hablantes. La fortaleza y vitalidad de las lenguas ancestrales tendrían resultados favorables en una serie de características culturales y sociales de los grupos y de la

122 Incluso, el presidente Juan Manuel Santos, en el mensaje enviado a las autoridades tradicionales, dirigentes indígenas y comunidades presentes en la minga de pensamiento convocada el 12 de octubre de 2012 para conmemorar el centenario del holocausto cauchero de cerca de 80.000 indígenas del Amazonas, tuvo oportunidad de ir más allá de pedir perdón y, como lo expresaron los dirigentes indígenas, comprometerse a "garantizarle a estos pueblos su pervivencia cultural y la existencia en todas sus manifestaciones" (oNIC, 2012); en especial, de anunciar medidas reparativas por las graves consecuencias que tanta violencia tuvo en las prácticas lingüísticas de las comunidades victimizadas. Las disculpas del Presidente colombiano se parecieron más a las ofrecidas a los pueblos indígenas en Australia y los Estados Unidos, las cuales no vinieron con acciones concretas de índole reparativa. comunidad, como la cohesión, la cosmovisión, la supervivencia cultural, las estructuras sociales, las relaciones con la tierra y los recursos, la continuación de las prácticas agrícolas, entre otras. Por lo anterior, merecería más atención como un elemento central de la reparación transformadora que se pretende emprender en Colombia para remediar a las víctimas de las violencias y otras injusticias de su presente y su pasado.

\section{CONCLUSIÓN}

Como señaló Pou Giménez (2012), “tomar en serio el multilingüismo constitucional y orientarlo al desarrollo de políticas lingüísticas no transicionales, no simbólicas y más equitativas podría ser una manera de crear vías de desarrollo para personas que, en América Latina, se sobreponen largamente con las más pobres." Ahora Colombia se encuentra entre los países latinoamericanos que han promulgado una legislación que tiene por objeto proteger las lenguas indígenas y respetar los derechos de sus hablantes. Tales leyes asignan a los Estados un conjunto de responsabilidades que se alinean con las obligaciones internacionales y con las prioridades demostradas por los pueblos indígenas.

De esta manera, el progreso hacia la justicia reparativa lingüística se podría materializar a través del desarrollo de acciones estatales adicionales a las bases establecidas por la Ley de Lenguas, y en el caso de comunidades afectadas por el conflicto armado, con medidas complementarias a las definidas en el Decreto-Ley 
4633 de 2011. No obstante, Colombia ha sido criticada por tener una estructura normativa de buenas intenciones que contrasta agudamente con la realidad. Si los órganos estatales competentes no logran materializar la protección respecto a las lenguas indígenas y los derechos lingüísticos, la brecha entre la ley y la realidad se agravará. El triste resultado: mientras la Constitución colombiana en el papel continúe proclamando con orgullo la diversidad étnica del país y la única voz que se siga escuchando sea en español, todas las otras voces habrán caído en el silencio.

\section{Bibliografía}

Agencia EFE. (6 de junio, 2013). Reino Unido compensará con 23 millones de euros a los Mau Mau de Kenia. Recuperado de http:// www.eltiempo.com/mundo/africa/ARTICULOWEB-NEW_NOTA_INTERIOR-12849864.htm!.

Aguirre Licht, D. (2004). Estudios en lenguas aborígenes y etnoeducación en Colombia. Revista Educación y Pedagogía, 39, 29-40.

Anaya, S. J. (2004). Indigenous Peoples in International Law. New York: Oxford University Press.

Arzoz, X. (2009). Language Rights as Legal Norms. European Public Law, 15(4), 541-574.

Australian Human Rights Commission. (2009). Aboriginal \& Torres Strait Islander Social Justice Report 2009. Recuperado de http:// www.humanrights.gov.au/sites/default/files/ content/social_justice/sj_report/sjreport09/ pdf/sjr_2009_web.pdf

Australian Institute of Aboriginal and Torres Strait Islander Studies -AIATSIS. (2005). National Indigenous languages survey report 2005. Canberra: Department of Communications, Information Technology and the Arts.

Bacca Benavides, P.I. (2009). Tiempo y espacio de las reparaciones colectivas para los pueblos indígenas víctimas de la violencia. En R. Uprimny Yepes, A.P. Bolivar Jaime, D.E. Guzmán Rodríguez (Eds.), Reparaciones en Colombia: análisis y propuestas (pp. 169-217). Bogotá: Universidad Nacional de Colombia.

Bottigliero, I. (2004). Redress for victims of crimes under international law. Leiden: Martinus Nijhoff.

Castle, S. (20 October 2013). Caribbean Nations to Seek Reparations, Putting Price on Damage of Slavery. New York Times. Recuperado de http://www.nytimes.com/2013/10/21/ world/americas/caribbean-nations-to-seekreparations-putting-price-on-damage-of-slavery.html?pagewanted $=1 \& \_r=0$.

Charters, C. (2008). Reparations for indigenous peoples: Global international instruments and institutions. En F. Lenzerini (Ed.). Reparations for Indigenous Peoples: International and comparative perspectives (pp. 163-196). Oxford: Oxford University Press. 
Clavero, B. (2008). Genocide or Ethnocide, 1933-2007. How to Make, Unmake, and Remake Law with Words. Milano: Giuffrè Editore.

Comité de Derechos Económicos, Sociales y Culturales de las Naciones Unidas -CDESC. (1990). Observación General 3: Índole de las obligaciones de los Estados partes (art. 2, párr. 1 del Pacto. E/1991/23. Recuperado de http://conf-dts1.unog.ch/1\%20 SPA/Tradutek/Derechos_hum_Base/CESCR/00_1_obs_grales_Cte\%20Dchos\%20 Ec\%20Soc\%20Cult.html

Comité de Derechos Económicos, Sociales y Culturales de las Naciones Unidas. (2009a). Observación general . $^{\circ}$ 20: La no discriminación y los derechos económicos, sociales y culturales (artículo 2, párr. 2 del Pacto Internacional de Derechos Económicos, Sociales y Culturales), E/C.12/ GC/20. Recuperado de http://www.refworld. org/cgi-bin/texis/vtx/rwmain/opendocpdf. pdf?reldoc $=$ y\&docid $=4 a e 049 a 62$

Comité de Derechos Económicos, Sociales y Culturales de las Naciones Unidas. (2009b). Observación General n. ${ }^{\circ}$ 21: Derecho de toda persona a participar en la vida cultural (artículo 15, párr. 1 a) del Pacto Internacional de Derechos Económicos, Sociales y Culturales. E/C.12/GC/21. Recuperado de http://www. refworld.org/cgi-bin/texis/vtx/rwmain/opendocpdf.pdf?reldoc=y\&docid=4ed35beb2

Comité de Derechos Humanos. (1989). Observación general $n .^{\circ} 18$ relativa a la no discriminación. Recuperado de http:// www.acnur.org/t3/fileadmin/scripts/doc. php?file=biblioteca/pdf/1404

Comité de Derechos Humanos. (1994). Observación general $n .^{\circ}$ 23: Derechos de las minorías (artículo 27). Recuperado de http:// conf-dts1.unog.ch/1\%20SPA/Tradutek/Derechos_hum_Base/CCPR/00_2_obs_grales_ Cte\%20DerHum\%20\%5BCCPR\%5D.html

Comité de Derechos Humanos. (2000). J. G. A. Diergaardt Vs. Namibia, Comunicación n. ${ }^{\circ}$ 760/1997. U. N. Doc. CCPR/ C/69/D/760/1997.

Comité de los Derechos del Niño. (2009). Observación General n. ${ }^{\circ} 11$ : los niños indígenas y sus derechos en virtud de la Convención. CRC/C/GC/11, 12 de febrero de 2009.

Comité para la Eliminación de la Discriminación Racial -CERD. (1997). Recomendación general $n .{ }^{\circ}$ XXIII relativa a los derechos de los pueblos indígenas. $51^{\circ}$ período de sesiones. UN Doc. HRI/GEN/1/Rev.7. Recuperado de http:// conf-dts1.unog.ch/1\%20SPA/Tradutek/Derechos_hum_Base/CERD/00_3_obs_grales_ CERD.html

Commonwealth Ombudsman. (2011). Talking in language: Indigenous language interpreters and government communication. Australian Commonwealth Ombudsman. Recuperado de http://www.ombudsman.gov.au/files/Talking_in_Language-Indigenous_Interpreters_ REPORT-05-2011.pdf 
Consejo Económico y Social de las Naciones Unidas. (2007). Restoration of indigenous toponyms: recognition of attachment, identity and dependence. UN Doc. E/CONF.98/41.

Corte Interamericana de Derechos Humanos -CIDH. (2004). Masacre Plan de Sánchez vs. Guatemala. Reparaciones y costas. Sentencia de 19 de noviembre de 2004. Serie C, n. ${ }^{\circ}$ 116.

Corte Interamericana de Derechos Humanos. (2005). Caso Comunidad Indígena Yakye Axa vs. Paraguay. Fondo, reparaciones y costas. Sentencia 17 de junio de 2005. Serie C, n. ${ }^{\circ}$ 125.

Corte Interamericana de Derechos Humanos. (2006). López Álvarez vs. Honduras. Fondo, reparaciones y costas. Sentencia de 1 de febrero de 2006. Serie C, n. 141.

Corte Interamericana de Derechos Humanos. (2007). Pueblo Saramaka vs. Suriname. Excepciones preliminares. Fondo, reparaciones y costas. Sentencia de 28 de noviembre de 2007. Serie C, n. ${ }^{0} 172$.

Corte Interamericana de Derechos Humanos. (2010). Comunidad indígena Xákmok Kásek vs. Paraguay. Fondo, reparaciones y costas. Sentencia de 24 de agosto de 2010. Serie C, n. 214.

Crystal, D. (2000). Language Death. Cambridge: Cambridge University Press.
Dixon, R. M. W. (1997). The rise and fall of languages. Cambridge: Cambridge University Press.

Dussias, A. M. (2008). Indigenous Languages under Siege: The Native American Experience, 3 Intercultural Human Rights Law Review 5.

Edwards, J. (2010). Minority Languages and Group Identity: Cases and Categories. Amsterdam, Philadelphia: John Benjamins Publishing Company.

Edwards, S. E. y Heinrich, M. (2006). Redressing cultural erosion and ecological decline in a far North Queensland aboriginal community (Australia): the Aurukunethnobiology database project. Environment, Development and Sustainability, 8, 569-583.

Enciso Patiño, P. (2004). Estado del arte de la etnoeducación en Colombia. Bogotá: Ministerio de Educación Nacional.

Evans, C. (2012). The right to reparation in international law for victims of armed conflict. Cambridge: Cambridge University Press.

Fishman, J. A. (1991). Reversing Language Shift. Clevedon, UK: Multilingual Matters.

Francioni, F. (2008). Reparations for Indigenous Peoples: Is International Law Ready to Ensure Redress for Historical Injustices? En F. Lenzerini (Ed.). Reparations for Indigenous Peoples: International and comparative perspectives (pp. 27-45). Oxford: Oxford University Press. 
Gafner-Rojas, C. M. (2008). La diversidad lingüística en Colombia - Protección jurídica de las lenguas indígenas. Pensamiento Jurídico, 22, 253-258.

Göcke, K. (2010). The Case of Ángela Poma Poma v. Perú before the Human Rights Committee. Max Planck Yearbook of United Nations Law, 14, 337-370.

Gorter, D. y Cenoz, J. (2012). Legal Rights of linguistic minorities in the European Union. En P. Tiersma y L. Solan (Eds.). Oxford Handbook of Language and Law (pp. 261-271). Oxford: Oxford University Press.

Greiff de, P. (2006). Justice and Reparations. En P. de Greiff (Ed.). The Handbook of Reparations (pp. 451-477). Oxford: Oxford University Press.

Grenoble, L. A. y Whaley, L. J. (2006). Saving languages: An introduction to language revitalization. Cambridge: Cambridge University Press.

Harmon, D. y Loh, J. (2010). The Index of Linguistic Diversity: A New Quantitative Measure of Trends in the Status of the World's Languages. Language Documentation and Conservation, 4, 97-151.

Harrison, D. K. (2007). When Languages Die: The Extinction of the World's Languages and the Erosion of Human Knowledge. Oxford: Oxford University Press.
Higgins, N. (2003). The Right to Equality and Non-Discrimination with regard to Language. Murdoch University Electronic Journal of Law, 10(1). Recuperado de http://www.austlii.edu. au/au/journals/MurUEJL/2003/7.html

Hornberger, N. H. y King, K. A. (1996). Language Revitalization in the Andes: Can the Schools Reverse Language Shift? Journal of Multilingual and Multicultural Development, 17(6), 427-441.

International Law Association. (2012). Final Report. Committee: Rights of Indigenous Peoples, Sofia Conference 2012. Recuperado de http://www.ila-hq.org/en/committees/index.cfm/cid/1024

International Law Commission. (November, 2001). Draft Articles on Responsibility of States for Internationally Wrongful Acts. Supplement No. 10 (A/56/10), chp.IV.E.1. Recuperado de http://www.unhcr.org/refworld/ docid/3ddb8f804.html.

Krauss, M. E. (1992). The world's languages in crisis. Language, 68, 4-10.

Landaburu, J. 2004. La situación de las lenguas indígenas de Colombia: prolegómenos para una política lingüística viable. Amérique Latine Histoire et Mémoire, 10. Recuperado de http://alhim.rvues.org/document125.html.

Lemaitre Ripoll, J. (Ed.). (2013). La Quintiada (1912-1925). La rebelión indígena liderada por Manuel Quintín Lame en el Cauca. Reco- 
pilación de fuentes primarias. Bogotá: Universidad de los Andes.

Lenzerini, F. (Ed.). (2008). Reparations for indigenous peoples: international and comparative perspectives. Oxford: Oxford University Press.

Maffi, L. (2001). On the interdependence of biological and cultural diversity. In Maffi, L. (Eds.). On Biocultural Diversity: Linking Language, Knowledge, and the Environment (pp. 1-50). Washington, DC: Smithsonian Institution Press.

Magarrell, L. (2007). Reparations in Theory and Practice. ICTJ. Recuperado de http://ictj.org/ sites/default/files/ICTJ-Global-ReparationsPractice-2007-English.pdf

May, S. (2012). Language and Minority Rights. ( $2^{\mathrm{a}}$ ed.). New York: Routledge.

Mejía de, A-M. y Montes Rodríguez, M. E. (2008). Points of Contact or Separate Paths: A Vision of Bilingual Education in Colombia. En A-M. de Mejía y C. Helot (Eds.). Forging Multilingual Spaces: Integrated Perspectives on Majority and Minority Bilingual Education (pp.109139). Bristol, UK: Multilingual Matters.

Mosquera, Rosero-Labbé \& Barcelos (Eds.). (2007) Afro-Reparaciones: Memorias de la esclavitud y justicia reparativa para negros, afrocolombianos y raizales. Bogotá: Universidad Nacional de Colombia.
Mufwene, S. S. (2005). Globalization and the myth of killer languages. En G. Huggan y S. Klassen (Eds.). Perspectives on Endangerment (pp. 19-48). Hildesheim/New York: Georg OIms Verlag.

National Inquiry into the Separation of Aboriginal and Torres Strait Islander Children from Their Families. (1997). Bringing them Home: Report of the National Inquiry into the Separation of Aboriginal and Torres Strait Islander Children from Their Families. Sydney: Human Rights and Equal Opportunity Commission.

Nettle, D. y Romaine, S. (2000). Vanishing Voices: The Extinction of the World's Languages. Oxford: Oxford University Press.

Organización de las Naciones Unidas para la Educación, la Ciencia y la Cultura -Unesco. (2003). Vitalidad y peligro de desaparición de las lenguas. Grupo especial de expertos sobre las lenguas en peligro convocado por la Unesco. Documento adoptado por la Reunión Internacional de Expertos sobre el programa de la Unesco "Salvaguardia de las Lenguas en Peligro" París, 10-12 de marzo de 2003. CLT/CEI/DCE/ELP/PI/2003/1. Recuperado de http://unesdoc.unesco.org/ images/0018/001836/183699S.pdf

Organización Nacional Indígena de Colombia onIc. (30 de octubre de 2012). A cien años del holocausto cauchero en el Amazonas. Recuperado de http://cms.onic.org.co/2012/10/ a-100-anos-del-holocausto-cauchero-en-elamazonas/ 
Pasqualucci, J. M. (2006). The Evolution of International Indigenous Rights in the Inter-American Human Rights System. Human Rights Law Review, 6(2), 281-322.

Pineda Camacho, R. (2000). El derecho a la lengua. Una historia de la política lingüística en Colombia. Bogotá: Ediciones Uniandes.

Posner, E. y Vermeule, A. (2003). Reparations for slavery and other historical injustices. Columbia Law Review, 103(3), 689-748.

Pou Giménez, F. (2012). Constitucionalismo y derechos lingüísticos en América Latina: una discusión preliminar. En A. do Amaral (Ed.). El constitucionalismo en transición. SELA 2011 (pp. 75-99). Buenos Aires: Libraria Ediciones.

Primera, M. (3 de agosto de 2013). El Caribe reclama a Europa una compensación por la esclavitud. El País. Recuperado de http://internacional.elpais.com/internacional/2013/08/03/ actualidad/1375558119_801842.html

Rodríguez-Garavito, C. A. y Lam, Y. (2011). Etnorreparaciones: la justicia colectiva étnica y la reparación a pueblos indígenas y comunidades afrodescendientes en Colombia. Bogotá: DeJusticia.

Rodriguez-Piñero, L. (2011). Inter-American System and the UN Declaration on the Rights of Indigenous Peoples: Mutual Reinforcement. En S. Allen y A. Xanthaki. (Eds). Reflections on the UN Declaration on the Rights of Indi- genous Peoples (pp. 457-484). Oxford: Hart Publishing.

Schabas, W. (2000). Genocide in International Law. Cambridge: Cambridge University Press.

Shelton, D. (2005). Remedies in international human rights law. Oxford: Oxford University Press.

Skutnabb-Kangas, T. (2000). Linguistic Genocide in Education - or World-wide Diversity and Human Rights. Mahwah, NJ: Lawrence Erlbaum Associates.

Skutnabb-Kangas, T. y Dunbar, R. (2010). Indigenous children's education as linguistic genocide and a crime against humanity? A global view. Gáldu čála - Journal of Indigenous Peoples Rights, 1.

Thompson, J. (2002). Taking responsibility for the past: reparation and historical injustice. Cambridge, UK: Polity; Malden, MA: Blackwell Publishers.

Triana y Antorveza, H. (1987). Las lenguas indígenas en la historia social del Nuevo Reino de Granada. Bogotá: Instituto Caro y Cuervo.

Tsosie, R. (2007). Acknowledging the past to heal the future: the role of reparations for native nations. En J., Miller y R., Kumar. (eds). Reparations: interdisciplinary inquiries (pp. 43-68). New York: Oxford University Press.. 
Tsunoda, T. (2005). Language Endangerment and Language Revitalization. Berlin; New York: Mouton de Gruyter.

United Nations Permanent Forum on Indigenous Issues -UNPFII. (2010). State of the World's Indigenous Peoples. United Nations Department of Economic and Social Affairs. Recuperado de http://www.un.org/esa/socdev/ unpfii/documents/SOWIP_web.pdf

Uprimny, R. y Guzmán, D. E. (2010). En búsqueda de un concepto transformador y participativo para las reparaciones en contextos transicionales. International Law, Revista Colombiana de Derecho Internacional, 17, 231-286.

Valls, A. (2007). Reconsidering the case for black reparations. En J. Miller y R. Kumar, Rahul (Eds.). Reparations: interdisciplinary inquiries (pp. 114-129). Oxford: Oxford University Press.

Varennes de, F. (1996). Language, minorities and human rights. The Hague, Boston: Kluwer Law International.

Varennes de, F. (2007). Language Rights as an Integral Part of Human Rights - A Legal Perspective. En M. Koenig y P. F. A. Guchteneire
(Eds.). Democracy and human rights in multicultural societies (pp.115-125). Aldershot, UK: Ashgate Publishing.

von Gleich, U. (Abril, 2010). Language and Sociopolitical Struggle in the Hispanic World. Ponencia en Simposio, Universidad de Newcastle, Reino Unido.

Vrdoljak, A. F. (2008). Reparations for cultural loss. En F. Lenzerini (Ed.). Reparations for indigenous peoples: international and comparative perspectives (pp. 197-228). Oxford: Oxford University Press.

Waldron, J. (1992). Superseding historic injustice. Ethics, 103(1), 4-28.

Wardhaugh, R. (1987). Languages in competition: dominance, diversity, and decline. London: Basil Blackwell Ltd.

Wiessner, S. (2011). The Cultural Rights of Indigenous Peoples: Achievements and Continuing Challenges. European Journal of International Law, 22(1), 121-140.

Yamamoto, E. K., Kim, S. H. Y. y Holden, A. M. (2007). American Reparations Theory and Practice at the Crossroads. California Western Law Review, 44(1), pp. 1-86. 